\title{
The potential role of the ESRRG pathway in placental dysfunction
}

\author{
Zhiyong Zou ${ }^{1}$, Karen Forbes ${ }^{1,2}$, Lynda K Harris ${ }^{1,3}$ and Alexander E P Heazell ${ }^{1,4}$ \\ ${ }^{1}$ Maternal and Fetal Health Research Centre, University of Manchester, St Mary's Hospital, Manchester, UK, ${ }^{2}$ Leeds \\ Institute of Cardiovascular and Metabolic Medicine, Faculty of Medicine and Health, University of Leeds, Leeds, UK, \\ ${ }^{3}$ Division of Pharmacy and Optometry, Faculty of Biology, Medicine and Health, University of Manchester, \\ Manchester, UK and ${ }^{4}$ St Mary's Hospital, Manchester Foundation Trust, Manchester Academic Health Science \\ Centre, Manchester, UK
}

Correspondence should be addressed to Z Zou; Email: zhiyong.zou@postgrad.manchester.ac.uk

\begin{abstract}
Normal placental development and function is of key importance to fetal growth. Conversely aberrations of placental structure and function are evident in pregnancy complications including fetal growth restriction (FGR) and preeclampsia. Although trophoblast turnover and function is altered in these conditions, their underlying aetiologies and pathophysiology remains unclear, which hampers development of therapeutic interventions. Here we review evidence that supports a role for estrogen related receptorgamma (ESRRG) in the development of placental dysfunction in FGR and preeclampsia. This relationship deserves particular consideration because ESRRG is highly expressed in normal placenta, is reduced in FGR and preeclampsia and its expression is altered by hypoxia, which is thought to result from deficient placentation seen in FGR and preeclampsia. Several studies have also found microRNA (miRNA) or other potential upstream regulators of ESRRG negatively influence trophoblast function which could contribute to placental dysfunction seen in FGR and preeclampsia. Interestingly, miRNAs regulate ESRRG expression in human trophoblast. Thus, if ESRRG is pivotally associated with the abnormal trophoblast turnover and function it may be targeted by microRNAs or other possible upstream regulators in the placenta. This review explores altered expression of ESRRG and upstream regulation of ESRRG-mediated pathways resulting in the trophoblast turnover, placental vascularisation, and placental metabolism underlying placental dysfunctions. This demonstrates that the ESRRG pathway merits further investigation as a potential therapeutic target in FGR and preeclampsia.

Reproduction (2021) 161 R45-R60
\end{abstract}

\section{Introduction}

Placental dysfunction describes when the placenta fails to develop and/or function adequately to support the nutritional demands of the fetus, and is central to the development of both fetal growth restriction (FGR) and preeclampsia (Redman 1991, Spinillo et al. 2019). FGR describes a fetus that does not reach its genetic growth potential. In clinical practice, this is often identified as a small for gestational age infant i.e. a baby whose estimated fetal weight (EFW) or birthweight is less than the $10^{\text {th }}$ percentile for that stage of pregnancy (ACOG 2019). However, being small for gestational age is not synonymous with FGR. True FGR affects 5\%-10\% of fetuses and is associated with both short-term and longterm complications including stillbirth, neonatal death, abnormal neurodevelopment, and cardiovascular and metabolic disorders in later life (Bernstein et al. 2000, Gardosi et al. 2005, Crispi et al. 2010, Ramirez-Velez et al. 2017, Pels et al. 2019). The majority of cases of FGR are mediated by abnormal placental structure and function (Spinillo et al. 2019). FGR may also co-exist with preeclampsia, which is defined as an elevation of maternal blood pressure with proteinuria occurring after 20 weeks' gestation (Brown et al. 2018). In addition to adverse effects on the fetus, preeclampsia is associated with maternal morbidity and mortality (Souza et al. 2013, Brown et al. 2018). Presently there are no effective therapies to treat FGR or preeclampsia, leaving a decision between expectant management or delivery indicated by deterioration in fetal or maternal condition. Therapeutic advances are in part impaired by an incomplete understanding of the mechanisms underlying the placental dysfunction evident in FGR and preeclampsia. Therefore, the identification of key causal pathways amenable to therapeutic manipulation is an important goal for research in this area. Here we review the evidence for involvement of one such pathway, that of estrogen-related receptor gamma (ESRRG) in the human placenta (Kumar \& Mendelson 2011).

Estrogen-related receptor-gamma is a member of the ERR family of orphan nuclear receptors, which is highly 
expressed in the human placenta (Takeda et al. 2009). Evidence suggests that ESRRG serves an important role in trophoblast differentiation, proliferation, and invasion, and may be involved in blood pressure homeostasis (Luo et al. 2014, Zhu et al. 2018a). In addition, deficient expression of ESRRG is linked to impaired placental mitochondrial function (Poidatz et al. 2012), which could lead to inadequate energy supply and thus reduced energy expenditure within the placenta. Due to its wide range of functions in relevant biological processes, it is plausible that ESRRG may also play a role in placental dysfunction underlying pregnancies complicated with FGR or preeclampsia.

To consider whether the ESRRG pathway has a causal role in placental dysfunction we have reviewed the literature to: (i) summarize knowledge regarding the role of ESRRG in trophoblast, placental vascularisation and placental metabolism, (ii) discuss the evidence for aberrant expression of constituents of the ESRRG pathway in pregnancy complications, including FGR and preeclampsia, and (iii) consider the implications of altered ESRRC expression and how this may contribute to placental dysfunction.

\section{Placental dysfunction underlying pregnancy complications}

To assess whether a pathway may be involved in the pathophysiology of FGR and/or preeclampsia, its role in normal placental development requires consideration, followed by evaluation of whether the aberrant placental phenotype seen in these conditions is consistent with disruption of that pathway.

\section{Normal placental development}

In normal placental development, appropriate differentiation of cytotrophoblast cells, the trophoblast stem cell population of the placenta, is important; two different pathways arise within the developing placental villus: the extravillous and villous lineages. The extravillous trophoblasts (EVT) differentiate from cytotrophoblast cell columns and invade the uterus (interstitial invasion) and spiral arteries (endovascular invasion) to remodel the maternal blood vessels and produce dilated and compliant uterine arterioles (Fig. $1 \mathrm{~A})$, thereby ensuring an adequate supply of oxygen and nutrients to support fetal growth (Pijnenborg et al. 1983). Proliferation, differentiation and fusion of villous cytotrophoblast maintains the syncytiotrophoblast, the multinucleated outer layer of the placenta responsible for placental transport, protective and endocrine functions (Jones \& Fox 1991) (Fig. 1A and B). The villous cytotrophoblast and syncytiotrophoblast, together with a core of villous stromal cells containing fetoplacental blood vessels form the villous tree, which is the functional unit of the placenta (Jones \& Fox 1991) (Fig. $1 \mathrm{~A}$ and $\mathrm{B})$. There are five different types of villi, including mesenchymal villi, immature intermediate villi, stem villi, mature intermediate villi, and terminal villi. Terminal villi, which represent the final branches of the villous tree, exhibit a high degree of capillarization and
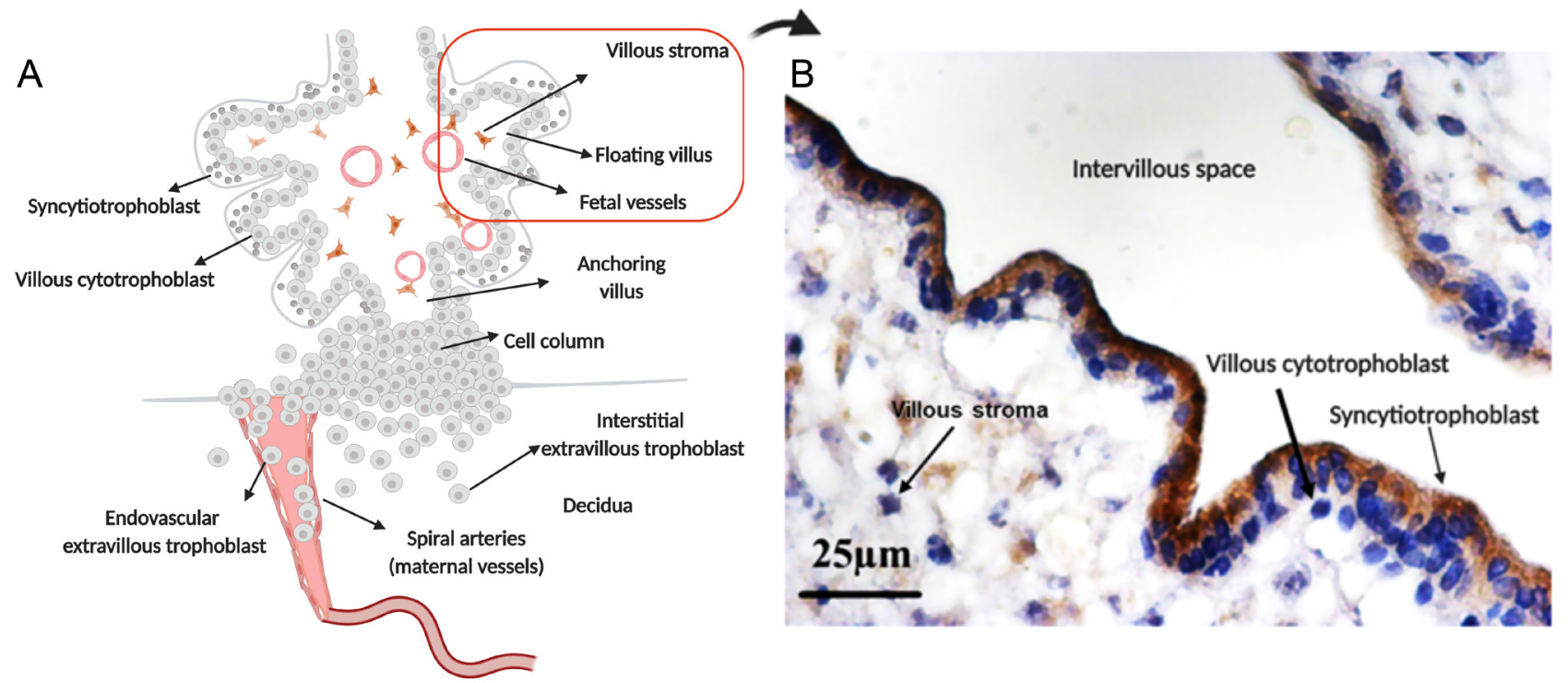

Figure 1 Schematic showing villous structure, trophoblast lineages and ESRRG localization in the human placenta. (A) Extravillous trophoblast that are situated at the end of the cell column invade the decidua and remodel the maternal spiral arterioles to produce dilated and compliant uterine vessels. Villous cytotrophoblast differentiates and fuses to form the outer multinucleated syncytiotrophoblast which transports nutrients and gases from the maternal to fetal circulation. (B) Light micrograph showing immunostaining of ESRRG in first trimester placental explants. ESRRG is mainly observed in the cytoplasm of the syncytiotrophoblast and cytotrophoblast. Arrows indicate villous cytotrophoblast, syncytiotrophoblast and villous stroma. Scale bar represents $25 \mu \mathrm{m}$. 
fetoplacental vessels are separated from maternal blood by a thin layer of syncytiotrophoblast and endothelial cells termed the vasculo-syncytial membrane, which is optimised for gas and nutrient exchange in human placenta (Kingdom et al. 2000). Consequently, there is a close relationship between terminal villous structure and function.

\section{Placental changes in FGR and preeclampsia}

Compared to placentas from normal pregnancies, placentas from pregnancies complicated by FGR and/ or pre-eclampsia may exhibit a number of structural and functional changes, including evidence of an unfolded protein response, increased trophoblast apoptosis and autophagy, and reduced trophoblast proliferation and metabolic function (Heazell et al. 2008, 2011, Curtis et al. 2013, Burton \& Jauniaux 2018, Yung et al. 2019). In the syncytiotrophoblast, some nuclei are aggregated to form syncytial knots with features of apoptosis and a disordered proliferation, and the increased formation of syncytial knots is related to the conditions of placental dysfunction which have been found in the FGR placentas (Macara et al. 1996, Heazell et al. 2007). FGR placentas also show decreased volume and surface area of terminal villi, with elongated and less-branched capillary loops (Jackson et al. 1995, Krebs et al. 1996). It is hypothesized that some of these changes in villous tissue are secondary to reduced invasion of extravillous trophoblast earlier in pregnancy, leading to impaired perfusion of the intervillous space. There may also be abnormalities of the fetal-placental vasculature and a reduction in placental weight, all of which combine to result in insufficient delivery of nutrients to the developing fetus (Roberts \& Post 2008).

The placenta is a metabolically active organ that consumes a large volume of oxygen throughout gestation, with energy provision mainly dependent on mitochondrial activity by glucose utilization (Diamant et al. 1975, Malek et al. 1996). An imbalance of placental mitochondrial function with excessive generation of reactive oxygen and nitrogen species in placentas is observed in pregnancy complications such as FGR, and pre-eclampsia (Atamer et al. 2005, Biri et al. 2007, Leduc et al. 2010). Taken together with the observation of altered perfusion of the intervillous space the critical relationship between hypoxia, reactive oxygen species (ROS), and how this leads to placental dysfunction needs to be considered.

\section{A possible role of hypoxia/ROS in placental dysfunction in FGR and preeclampsia}

As stated above, hypoxia and hypoxia-reoxygenation can contribute to the elevation of reactive oxygen species (ROS), which can lead to increased oxidative DNA damage and depletion of local antioxidant defenses (Hung \& Burton 2006, Kimura et al. 2013). Placental hypoxia has been reported in both FGR and preeclampsia (Kimura et al. 2013). Furthermore, a hypoxic environment can reproduce elements of the trophoblast phenotype seen in these conditions. Culture in $2 \%$ or $9 \% \mathrm{O}_{2}$ reduces differentiation and induces apoptosis in third trimester primary cytotrophoblast (Alsat et al. 1996, Levy et al. 2000). Culture in 2\% $\mathrm{O}_{2}$ impaired differentiation and invasion in first-trimester primary cytotrophoblast (Genbacev et al. 1996), and term placental villous explants also exhibited reduced proliferation and induction of apoptosis when cultured at $1 \%$ compared to $6-8 \% \mathrm{O}_{2}$ (Heazell et al. 2008). Therefore, oxygen tension can modulate both the development of villous structure and trophoblast function. The molecular mechanisms responsible for these changes in trophoblast phenotype are still elusive, but recent reports suggest that it may, in part, be linked to activation of an unfolded protein response (UPR) by placental oxidative stress (Yung et al. 2008, Yung et al. 2019).

To understand the potential contribution of the ESRRG pathway in the pathogenesis of placental dysfunction underlying FGR and preeclampsia, the functions of ESRRG in pregnancy will be described, and the evidence that ESRRG signalling might be involved in the occurrence of placental dysfunction will be reviewed.

\section{The ERR family}

Estrogen-related receptors (ERRs) are an NR3B (nuclear receptor $3 \mathrm{~B}$ ) group of the nuclear receptor subfamily, including ESRRA, ESRRB, and ESRRG, which are encoded by ESRRA, ESRRB, and ESRRG, respectively. The NR3B group of nuclear receptors is one of the larger NR3 classes and includes the hormone receptors for estrogen, androgens, progesterone, aldosterone, and cortisol (Giguere et al. 1988, Giguere 1999). Although ERRs share sequence homologies with the estrogen receptor (ER), the transcription of ERRs is not activated by estrogen, and information on the nature of endogenous ligands for ERRs remains to be established (Vanacker et al. 1999). ERRs can regulate transcription by binding to estrogen-related receptor elements (ERRE) in target genes, which include several molecules involved in the cellular energy metabolic pathway (Giguere 2008).

\section{Structure of ERRs}

According to their sequence homology and function, the structural features of ERRs include an activation function (AF)-1 domain/N-terminal domain (NTD), a DNAbinding domain (DBD), a ligand-binding domain (LBD), and an AF-2 domain (Giguere 1999). The NTD is a nonconserved domain and it includes an AF-1 domain and a variable amino acid domain. In ESRRG and ESRRA, the NTD contains phosphorylation-dependent sumoylation 
sites that are embedded in a synergy control motif and may serve a role in regulating the transcriptional activity of ERRs (Tremblay et al. 2008). The synergy control motif may have a role in modulating higher-order interactions among transcriptional factors (Iniguez-Lluhi \& Pearce 2000). The ERRs' DBD exists the highest sequence homology in the three ERR isoforms: ESRRB and ESRRA share $99 \%$ and $93 \%$ identical amino acid sequence with ESRRG respectively, which suggests that more than two ERRs might share some target genes (Heard et al. 2000). DBD contains two highly conserved zinc finger motifs, which recognize and bind a specific DNA sequence (TCAAGGTCA), denoted as an ERR response element (ERRE). The ERRE can be either a monomer, a homodimer, or a heterodimer, which can modulate the translational activities of ERRs (Johnston et al. 1997, Dufour et al. 2007). Moreover, ERRs and ERs have high homology in the DBD region (Giguere et al. 1988); ERRs can recognize the ERRE embedded in estrogen response elements (ERE), but only $21 \%$ of ESRRA target promoters can be recognized by ESR1 in breast cancer cell lines (Deblois et al. 2009). Despite this, several genes can be regulated by both ESR1 and ERRs, including the human lactoferrin gene and monoamine oxidase B (Yang et al. 1996, Zhang et al. 2006b).

The final structural part of ERRs is the LBD, a less conserved domain; there is a $77 \%$ sequence homology between the LBDs of ESRRB and ESRRG, and $61 \%$ homology between the ESRRA and ESRRG (Heard et al. 2000). The homodimerization or heterodimerization of LBD in ESRRG can also influence the translation of ERRs; the homodimerization of ESRRG via LBD can enhance the activity of translation; conversely, heterodimerization with ESRRA inhibits the activity of both receptors (Huppunen \& Aarnisalo 2004). The interaction between the LBD and its coactivator is ligand-independent (Greschik et al. 2002). However, the crystal structure also showed that the LBD can interact with ligands by a flexible ligand-binding pocket and importantly from the perspective of understanding receptor signalling pathways, several synthetic molecules can inhibit or stimulate the transcriptional function of ERRs by LBD, including proliferator-activated receptor coactivator 1-alpha, diethylstilbestrol (DES), and 4-hydroxytamoxifen (4-OH) (Tremblay et al. 2001a, Tremblay et al. 2001b, Kallen et al. 2004, Chao et al. 2006). Bisphenol A (BPA) is a chemical and environment contaminant used to produce plastics, which strongly binds to ESRRG--LBD (Takeda et al. 2009). As the level of BPA in maternal blood and placental tissue is inversely related to fetal weight in human pregnancy (Troisi et al. 2014), BPAmediated upregulation of placental ESRRG may provide a mechanistic link to explain the association between elevated BPA levels and FGR (Takayanagi et al. 2006, Okada et al. 2008).

Thus, the structure of the ERRs, specifically that of the LBD and DBD, is vital to the regulation of ERR signalling, including that of ESRRG. Furthermore, abnormal placental expression of ESRRG in FGR and preeclampsia suggests a potential role for ESRRG in the development or potentiation of these pregnancy complications (Luo et al. 2014, Zhu et al. 2018a). This review will consider how ESRRG is regulated, its effects in trophoblast and how this may contribute to the phenotypes of placental dysfunction observed in FGR and preeclampsia.

\section{ESRRG}

Both fetal and adult organs abundantly express ESRRC (Heard et al. 2000), including the placenta, heart, and brain (Heard et al. 2000, Takeda et al. 2009, Misra et al. 2017). ESRRG can regulate blood pressure homeostasis, due to the high expression of ESRRG in kidneys which mediate aldosterone-stimulated sodium and water reuptake (Alaynick et al. 2010). In Esrrg null mice, the genes that regulate serum potassium and blood pressure were decreased in the kidney; RNA expression of the potassium channels, Kcnj1, Kcne1, and Kcne2, and kallikrein-kinin system genes kallikrein 1 (KIk1) and kallikrein $6(K I k 6)$, were significantly reduced in the kidneys of Esrrg null mice (Alaynick et al. 2010). Other potential mechanisms by which Esrrg can regulate maternal blood pressure homeostasis during pregnancy are related to steroid 11 -hydroxylase (Cyp11b1) and aldosterone synthase (Cyp11b2) (Luo et al. 2014). In Esrrg heterozygous $\left(\mathrm{Esrrg}^{+-}\right)$pregnant mice, expression of Cyp11b1 and Cyp11b2 is decreased in the mouse adrenal cortex, resulting in reduced production of aldosterone and a reduction in blood pressure; conversely, expression of Cyp11b1 and Cyp11b2 in WT pregnant mice is increased after exposure to the Esrrg agonist DY131, which increased maternal blood pressure (Luo et al. 2014). Given that development of preeclampsia involves abnormal elevation of maternal blood pressure, dysregulation of ESRRG signaling in the kidney and adrenal cortex may contribute to this phenomenon.

Placental ESRRG expression also plays an important role in the maintenance of pregnancy. Placenta has the highest expression of ESRRG in the human reproductive system (Fig. 1B) (Takeda et al. 2009); expression of ESRRG increases over gestation and is higher in villous compared to extravillous trophoblast (Poidatz et al. 2012). ESRRG expression is dramatically increased during human cytotrophoblast cell differentiation, indicating a potential regulatory role (Kumar \& Mendelson 2011). Moreover, ESRRG also regulates genes involved in cellular energy homeostasis and metabolism; expression of key regulator genes involved in mitochondrial biogenesis (PGC1A and NRF1) and energy metabolism (PDK4 and MCAD) decreased after silencing ESRRG in human first trimester placental primary cytotrophoblast (Poidatz et al. 2012). As these studies indicate that ESRRG signaling may influence multiple aspects of 
normal placental function, we will review the evidence for the involvement of ESRRG in regulating trophoblast function, hypoxic responses, placental vascularisation, placental metabolism, and other regulators in the human placenta (Fig. 2 and Table 1).

\section{The effect of ESRRG on trophoblast function}

\section{Proliferation}

ESRRG knockdown has been shown to reduce proliferation of the extravillous-like trophoblast cell line HTR-8/SVneo, via decreasing the expression of its downstream gene, $17 \beta$-hydroxysteroid dehydrogenase type 1 (HSD17B1) (Zhu et al. 2018a). HSD17B1 is an enzyme capable of converting estrone to $17 \beta$-estradiol in the metabolism of estrogen. Abnormal expression of HSD17B1 has been reported in both FGR and preeclampsia (Zhu et al. 2018a); previous studies have revealed that a reduced plasma HSD17B1 expression level could be considered a potential prognostic factor for preeclampsia (Ishibashi et al. 2012, Ohkuchi et al. 2012). Ohkuchi et al. (2012) examined 128 normal pregnant women and 30 pregnancies complicated with preeclampsia and found that reducing maternal plasma levels of $H S D 17 B 1$ correlated with the occurrence of preeclampsia, implicating HSD17B1 in the pathogenesis of the disease, possibly by influencing the process of estrogen metabolism. Since estrogen can reduce

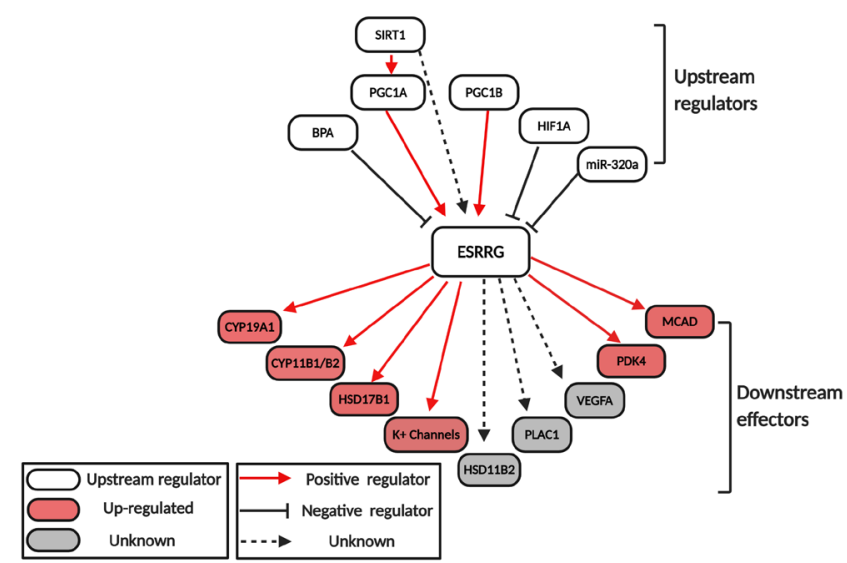

Figure 2 Diagrammatic representation of known upstream regulators and downstream effectors of ESRRG in the placenta. Expression of the depicted genes is known to be altered in the FGR or preeclampsia placenta, where a red arrow indicates a positive effect and a black line indicates a negative effect. Meanwhile, a black dot arrow suggests an unclear relationship between ESRRG and downstream effectors. CYP11B1: cytochrome P450 family 11 subfamily B member 1; HSD11B2: hydroxysteroid 11-beta dehydrogenase 2; HSD17B1: hydroxysteroid 17-beta dehydrogenase 1; PLAC1: placenta-specific 1; VEGFA: vascular endothelial growth factor $\mathrm{A}$; $P D K 4$ : pyruvate dehydrogenase kinase 4; MCAD: medium-chain acyl-CoA dehydrogenase; BPA: bisphenol A; PCG1A/B: peroxisome proliferator-activated receptor- $\gamma$ coactivator-1 alpha/beta; HIF1A: Hypoxia-inducible factor 1 -alpha. the proliferation of HTR-8/SVneo cell line (Patel et al. 2015), this might suggest a relationship between low level of $H S D 17 B 1$ in maternal serum, placental estrogen metabolism, and trophoblast proliferation. Moreover, the mRNA and protein level of HSD17B1 was decreased in placentas complicated with FGR (Zhu et al. 2018a). Therefore, aberrant regulation of HSD17B1 by ESRRG may contribute to placental dysfunction, by its ability to regulate the proliferation of cytotrophoblast cells which is disrupted in FGR and preeclampsia.

\section{Differentiation}

There is also evidence that ESRRG may influence cytotrophoblast differentiation via its role as a regulator of the aromatase CYP19A1, the voltage-gated potassium $\left(K_{\mathrm{v}} 7\right)$ channel family, or via interactions with two other downstream genes, placenta specific-1 (PLAC1), and 11ß-hydroxysteroid dehydrogenase 2 (HSD11B2).

The cytochrome P-450 (CYP) family members include CYP11A1 and CYP19A1, and hydroxysteroid dehydrogenases (HSDs), such as $3 \beta-\mathrm{HSD}$ and $17 \beta-$ HSD; these enzymes play a vital role in placental hormone synthesis and metabolism (Payne \& Hales 2004). C19 steroid precursors can be converted into estrogen via activating aromatase P450, which is encoded by the CYP19A1 gene and only expressed in the syncytiotrophoblast, not in trophoblast stem cells or cytotrophoblast (Fournet-Dulguerov et al. 1987, Kamat et al. 1998). Notably, ESRRG has been shown to stimulate the expression of CYP19A1 in vitro, via binding to its promotor to increase estrogen levels in a $20 \% \mathrm{O}_{2}$ culture environment, which promotes trophoblast differentiation. When human secondtrimester primary cytotrophoblasts were cultured in a hypoxic environment $\left(2 \% \mathrm{O}_{2}\right)$, both ESRRG and CYP19A1 expression decreased; however, elevating ESRRG expression restored CYP19A1 expression (Kumar \& Mendelson 2011).

ESRRG also induces mRNA and protein expression of the $K_{\mathrm{v}} 7$ family of potassium channels to regulate the differentiation of cytotrophoblast in second-trimester placentas. Voltage-gated $\mathrm{K}_{\mathrm{V}} 7$ channels are encoded by the KCNQ1-5 ( $\alpha$-subunit) and KCNE1-5 ( $\beta$-subunit) genes. The human placenta expresses many potassium channel genes, including the KCNQ and KCNE families, and the expression of KCNQ3 and KCNE5 is markedly increased in placentas from pregnancies complicated with preeclampsia, particularly in the syncytiotrophoblast (Mistry et al. 2011). ESRRG induces mRNA and protein expression of the potassium channels KLK1, KCNQ1, KCNE1, KCNE3 and KCNE5 during primary cytotrophoblast differentiation, the effect of which was blocked by hypoxia (Luo et al. 2013). After examining the promoter, an ERRE located in the upstream region of the KCNE1 and KLK1 genes was identified, to which ESRRG can bind (Luo et al. 2013). In addition, 


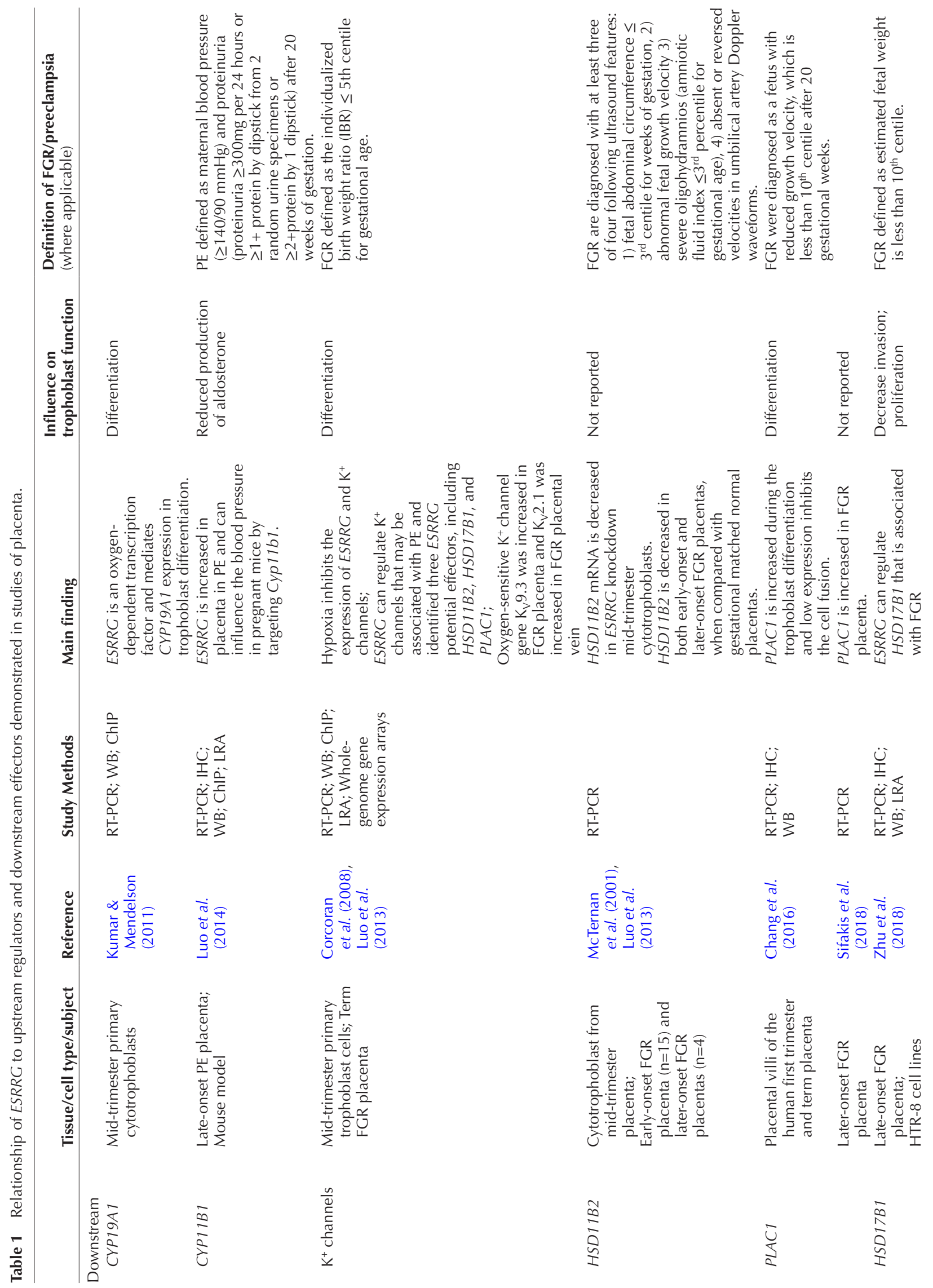



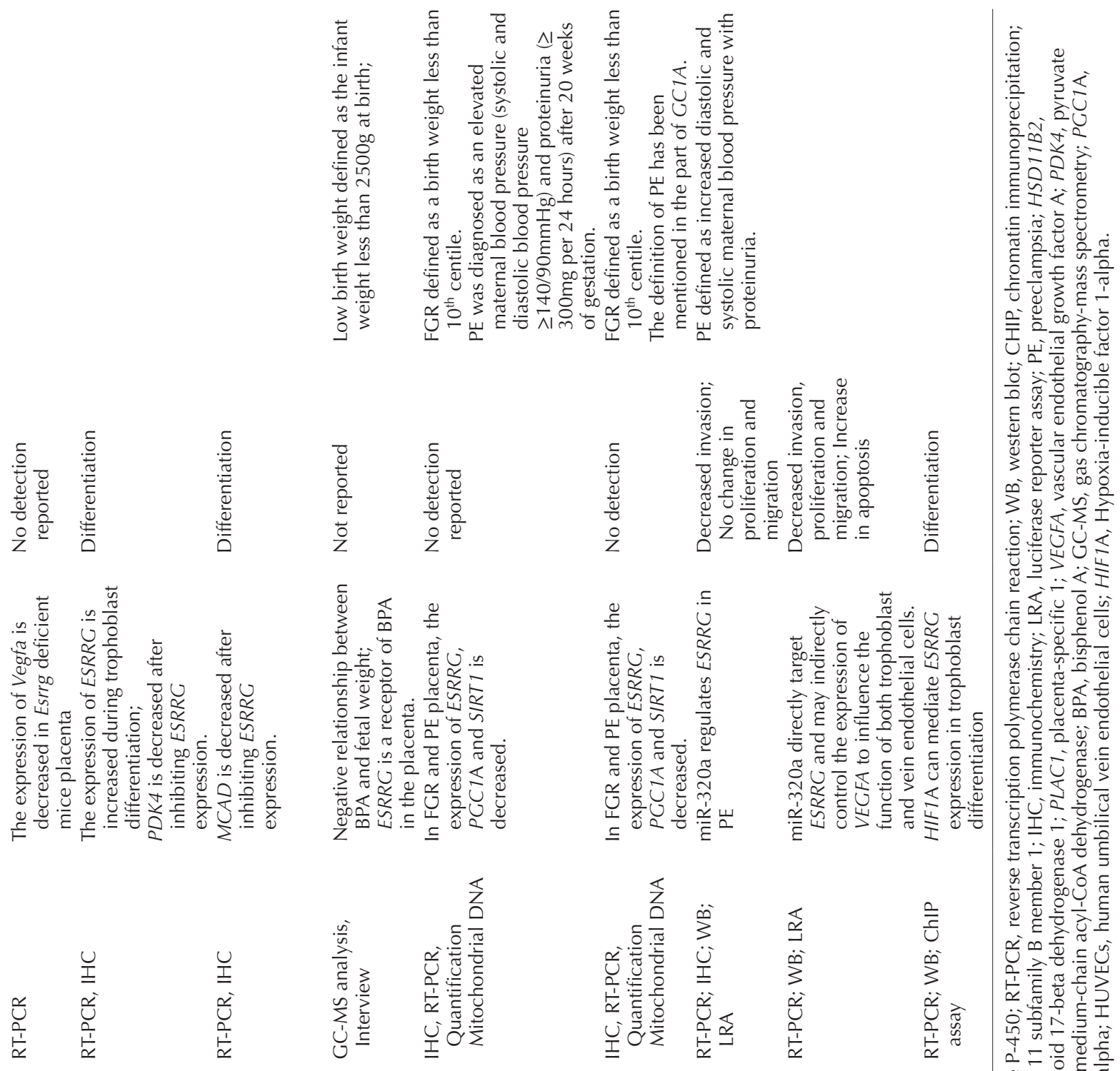

市 $匚$

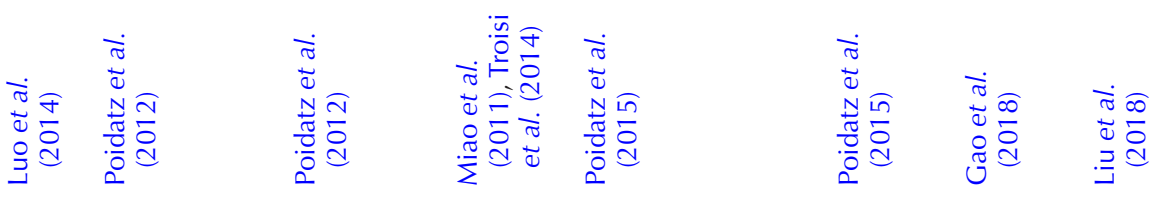
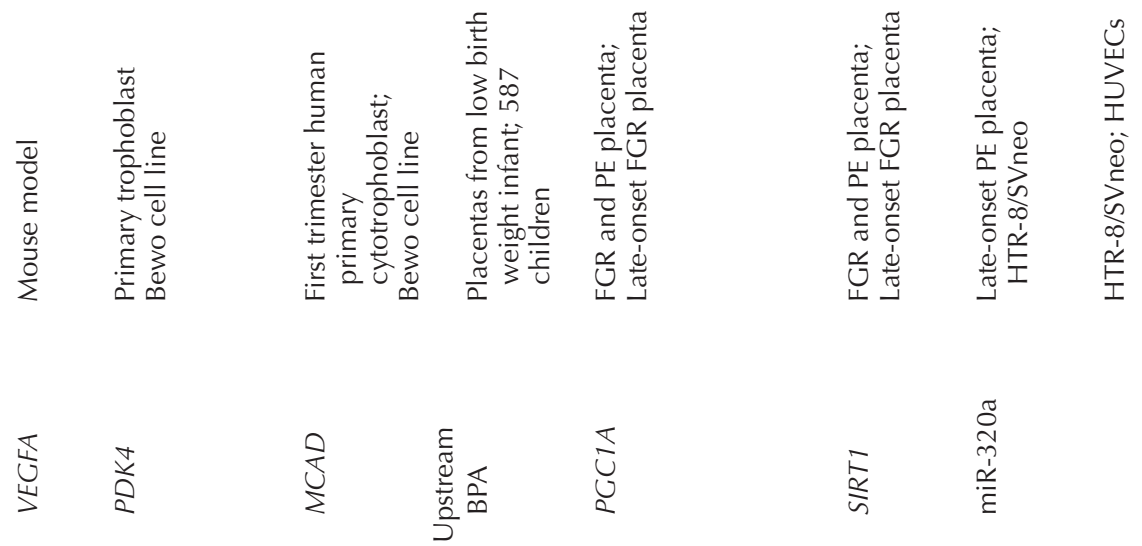

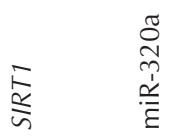

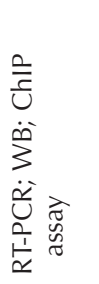

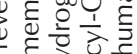

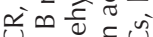

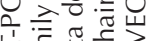

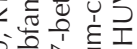

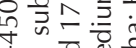

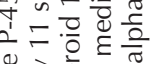

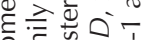

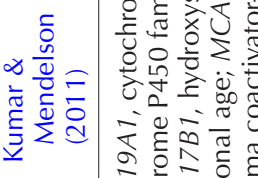

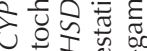

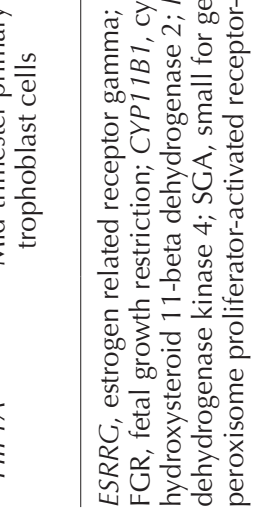


expression of the oxygen-sensitive $\mathrm{K}^{+}$channel gene $K_{\mathrm{v}} 9.3$ was increased in FGR placentas, and expression of $K_{\mathrm{v}} 2.1$ was increased in chorionic plate veins from the same placentas (Corcoran et al. 2008). However, the relationship between ESRRG and expression of $\mathrm{K}^{+}$ channels in functionally deficient placentas remains unclear.

There is also evidence that PLAC1 and HSD11B2 are downstream effectors of ESRRG, and these two genes can regulate cytotrophoblast differentiation (Luo et al. 2013). The expression of PLAC1 is elevated during trophoblast differentiation and conversely, reduced expression of PLAC1 attenuates fusion of term primary human cytotrophoblast in vitro (Chang et al. 2016). Contrary to expectations, Sifakis et al. found high PLAC1 expression in FGR placentas at term (Sifakis et al. 2018), although this may be linked to the aberrant differentiation and trophoblast turnover reported in FGR (Heazell et al. 2011, Huppertz 2011). Combined with the observations of Luo et al. these data suggest that the effect of PLAC1 on trophoblast differentiation might be mediated via ESRRG.

Another downstream gene of ESRRG is $H S D 11 B 2$, an enzyme that converts active cortisol to inactive cortisone, which is expressed in villous syncytiotrophoblast (Pepe et al. 1999). Both mRNA and protein expression of HSD11B2 is induced during term primary cytotrophoblast differentiation, and it is considered a marker for trophoblast differentiation (Hardy \& Yang 2002, Homan et al. 2006). During pregnancy, HSD11B2 acts as a critical placental glucocorticoid barrier that protects the fetus from the harmful effects of excessive maternal glucocorticoids (Benediktsson et al. 1993, Zhu et al. 2018b). Placental HSD11B2 expression correlates with fetal weight and postnatal growth velocity (Benediktsson et al. 1993). McTernan et al. (2001) showed that placental HSD11B2 expression is decreased in FGR and demonstrated the importance of placental HSD11B2 in regulating fetal growth. Studies of SGA placentas also reported low HSD11B2 expression, which further revealed the relationship between HSD11B2 and fetal weight (Struwe et al. 2007). Placental HSD11B2 expression at birth is positively associated with fetal length at birth, whereas its expression is inversely related to growth velocity in the first year of life, and might therefore be a predictor of postnatal growth of fetuses with FGR (Tzschoppe et al. 2009). These studies support the relationship between abnormal differentiation of cytotrophoblast seen in FGR and preeclampsia and expression of HSD11B2, although the roles of $H S D 11 B 2$ in trophoblast function are still unclear. As ESRRG regulates HSD11B2 (Luo et al. 2013), the reduced effect of HSD11B2 on trophoblast differentiation might be due to reduced levels of ESRRG in the presence of placental dysfunction.
Invasion

Invasion of the extravillous trophoblast into the uterine wall and subsequent remodeling of the uterine arterioles is critical for normal placental development and optimal uteroplacental perfusion. Knockdown of ESRRG resulted in the deficient invasion of the extravillous-like HTR-8/ SVneo cell line (Liu et al. 2018, Zhu et al. 2018a). Liu et al. showed that overexpression of microRNA (miR)320a inhibited HTR-8/SVneo invasion by regulating ESRRG signalling (Liu et al. 2018). Furthermore, Zhu et al. demonstrated that reduced expression of ESRRG in HTR-8/ SVneo cells significantly impaired invasion via regulation of HSD17B1 (Zhu et al. 2018a). Although a potentially significant finding, the relationship between ESRRG and the invasive capacity of extravillous trophoblast needs to be explored further using primary tissues.

\section{The effect of ERR $\gamma$ on response to hypoxia}

Ahypoxic environmentalters the expression of manygenes which are associated with trophoblast differentiation. The most well-studied oxygen sensor in trophoblast is hypoxia-inducible factor $1 \alpha$ (HIF1A), which is reported to be elevated in FGR and pre-eclampsia (Rajakumar et al. 2004, Robb et al. 2017). HIF1A regulates ESRRG expression in human trophoblast: culture in a $2 \%$ $\mathrm{O}_{2}$ environment activates HIF1A and decreases the expression of ESRRG and CYP19A1 (Kumar \& Mendelson 2011). Conversely, knockdown of HIF1A in trophoblast prevents ESRRG suppression under hypoxic conditions (Kumar \& Mendelson 2011). Collectively, these findings demonstrate that ESRRG serves as an oxygen-dependent transcriptional factor regulated by HIF1A to control the expression of downstream CYP19A1. This relationship appears to be maintained in vivo, as low ESRRG expression has been reported in placentas from FGR pregnancies, which often show evidence of hypoxia and/or oxidative stress (Takagi et al. 2004). A preliminary study in a south Chinese population examined the mRNA and protein level of ESRRG in 28 FGR placentas and 30 matched appropriate for gestational age (AGA) placentas, and reported lower expression of ESRRG in FGR placentas (Zhu et al. 2018a). Poidatz et al. (2015) also reported lower mRNA expression of ESRRG in 39 FGR placentas compared with a 30 controls in a European population. These studies support the hypothesis that ESRRG might play a role in placental dysfunction originating from placental hypoxia.

\section{The effect of ESRRG on placental vascularisation}

Although the trophoblast is critically important to the placental function, it is also widely acknowledged that impaired placental blood vessel development may be important in the aetiology of FGR (Hitschold 
et al. 1993). Several genes have been implicated in regulating placental vascularisation, including vascular endothelial growth factor A (VEGFA) (Ylikorkala et al. 2001, Burton et al. 2009). Maternal serum levels of VEGFA, an angiogenic factor that is crucial for placental angiogenesis during early gestation, are decreased in the $2^{\text {nd }}$ and $3^{\text {rd }}$-trimester in pregnancies complicated with FGR (Bersinger \& Odegard 2005). Expression of VEGFA in primary vascular endothelial cells is also reduced in FGR placentas (Chui et al. 2014). The altered vascularisation seen in the placentas of women with FGR can potentially be attributed to dysregulated ESRRG expression. In mice, placentas from Esrrg-/fetuses have significantly increased mRNA levels of Vegfa, compared with placentas from wild type fetuses (Luo et al. 2014), and in Esrrg ${ }^{+/-}$pregnant mice, circulating levels of the angiogenic, soluble receptor for VEGF, soluble fms-like tyrosine kinase-1(sFLT1), were significantly reduced (Luo et al. 2014). In the mouse myoblast cell line C2C12, suppression of Esrrg can block the transcriptional expression of Vegfa, whilst in HEK-293T cells, ESRRG has been shown to activate the VEGFA promoter (Matsakas et al. 2012). This indicates that ESRRG may affect placental vascularisation via its regulation of VEGFA, however further studies are required in humans to confirm this.

\section{ESRRG and placental metabolism}

There is accumulating evidence that ESRRG plays a role in the regulation of several mitochondrial functions, including mitochondrial biogenesis, oxidative phosphorylation, and fatty acid oxidation, in the heart, kidney, skeletal muscle, and placenta (Huss et al. 2002, Alaynick et al. 2007, Dufour et al. 2007, Kubo et al. 2009, Alaynick et al. 2010, Fan et al. 2018). In the human placenta, ESRRG regulates mitochondrial function by controlling gene networks involved in mitochondrial biogenesis and fat and glucose metabolism in the villous trophoblast, including pyruvate dehydrogenase kinase 4 (PDK4), medium chain acyl-CoA dehydrogenase (MCAD), sirtuin 1 (SIRT1) and peroxisome proliferatoractivated receptor gamma (PPARG) coactivator 1 alpha (PGC1A) (Poidatz et al. 2012).

In human term primary villous cytotrophoblast, expression of PDK4 and MCAD was decreased after knockdown of ESRRG expression (Poidatz et al. 2012), which implicates ESRRG as a potential regulator of placental fatty acid oxidation and glucose metabolism mediated via these genes. PDK4 can phosphorylate the pyruvate dehydrogenase complex (PDC), which facilitates the conversion of pyruvate to acetyl-CoA in mitochondria, to inhibit the activity of PDC (Sugden \& Holness 2003); MCAD is an enzyme which catalyzes the initial step of mitochondrial fatty acid oxidation (FAO) (Schulz 1991). ESRRG can stimulate the expression of PDK4 in human liver cell lines (HepG2 cells) and rat hepatoma cells (Zhang et al. 2006a, Lee et al. 2012); regulation of the promoter of $P D K 4$ by ESRRG has been observed in mammary epithelial cells by using both ChIP and luciferase reporter assays, and the activation of the ESRRG--PDK4 pathway attenuates glucose oxidation and decrease cell death and apoptosis (Kamarajugadda et al. 2012). Thus, a reduction in ESRRG would be expected to be associated with increased apoptosis and cell death, as is observed in FGR. This suggests that the ESRRG--PDK4 signalling pathway in human placentas might contribute to the placental dysfunction. MCAD is one of the targets of ESRRA and the increased expression of the ESRRA--MCAD pathway serves an important role in the decidualization of human primary endometrial stromal cells (Bombail et al. 2010). As ESRRG is similar to ESRRA, it is possible that ESRRG also contributes to the regulation of MCAD, however further studies are needed to investigate this and to determine the role of the pathway in placental dysfunction.

SIRT1, PCC1A, and PGC1B are also coactivators of ESRRG that have known roles in regulating placental metabolism. SIRT1, a NAD(+)-dependent protein deacetylase, is expressed ubiquitously in different organs and is required for many cellular processes related to differentiation and metabolism (Leibiger \& Berggren 2006). SIRT 1 is expressed in both the syncytiotrophoblast and cytotrophoblast (Lappas et al. 2011). Findings from two recent studies in mice indicate that SIRT1 plays a key role in trophoblast differentiation and placental development (McBurney et al. 2003, Arul Nambi Rajan et al. 2018). The differentiation of mouse trophoblast stem cells obtained from SIRT1-null mice was blunted in vitro (Arul Nambi Rajan et al. 2018), resulting in fetuses with FGR, and smaller placentas with deficient morphology including a thickened chorion and a more hypercellular labyrinth were observed (McBurney et al. 2003, Arul Nambi Rajan et al. 2018). Wilson et al. found SIRT1 can deacetylate and increases ESRRA DNA-binding activity by interacting with ESRRA in vivo and in vitro, which also suggests a potential interaction between ESRRG and SIRT1 (Wilson et al. 2010), as ESRRA and ESRRG have structural and functional similarities. In HepG2 cells, small heterodimer partner interacting leucine zipper protein (SMILE) expression and its ability to repress ESRRG transactivation and downstream signaling, is dependent on the expression of SIRT1 (Xie et al. 2009). SIRT1 can also positively regulate the expression of another ESRRG coactivator, PGC1A (Gerhart-Hines et al. 2007, Amat et al. 2009). PGC1A and its family member, $P G C 1 \mathrm{~B}$, act as transcriptional co-regulators of ESRRA and ESRRG to influence metabolism in many diseases, such as cardiovascular disease and cancer (Huss et al. 2002, Liu et al. 2005, Torrano et al. 2016, Luo et al. 2017). In human placental tissue, the mRNA expression level of PGC1A and SIRT1 correlated with that of ESRRG in pregnancies complicated with preeclampsia and FGR (Poidatz et al. 2015); low mRNA levels of ESRRG, PGC1A 
and SIRT1 have all been reported in FGR placentas (Poidatz et al. 2015). Together, these studies suggest that methods to modulate both ESRRG and its transcriptional co-regulators, may provide a potential therapeutic strategy to improve placental metabolism and fetal growth. Therefore, we will conclude by reviewing the miRNAs that have been identified as upstream regulators of ESRRG, and which may also contribute to the etiology of placental dysfunction.

\section{Regulation of ESRRG in the human placenta by miRNAs}

miRNAs are short non-coding RNAs with 19-23 nucleotides which post-translationally reduce gene expression in both animals and plants by mediating argonaute (AGO) binding to the 3'-untranslated-region (3'-UTR) of mRNA (Baek et al. 2008). The miRNA-induced silencing complex (miRISC), which includes the miRNAs and AGO, degrades target mRNA and represses protein translation. Different miRNAs are expressed in specific tissues, and by regulating different sets of target genes, specific miRNAs can mediate many cellular processes, such as differentiation, proliferation, and invasion (Anton et al. 2013, Li et al. 2014). In humans, more than $60 \%$ of protein-coding genes are thought to be regulated by miRNAs, many of which are specifically expressed in the placenta (Friedman et al. 2009). Expression of numerous miRNAs is altered in pregnancy complications such as FGR and preeclampsia, which are associated with placental dysfunction (Friedman et al. 2009, Zhang et al. 2010, Hromadnikova et al. 2015). The following miRNAs are associated with placental dysfunction and have been identified as potential upstream regulators of ESRRG.

miR-320a

miR-320a levels are increased in the placentas of women with late-onset preeclampsia, and overexpression of miR-320a in HTR-8/SVneo cells inhibits mRNA and protein expression of ESRRG (Gao et al. 2018). Key functional roles for ESRRG in the placenta appear to be modulated by miR-320a: direct regulation of ESRRG by miR-320a inhibits migration, invasion, and proliferation and indirectly modulates levels of VEGFA in both HTR-8/ SVneo cells and human umbilical vein endothelial cells (HUVECs) (Gao et al. 2018, Liu et al. 2018). However, to our knowledge, expression levels of miR-320a in FGR placentas has yet to be assessed.

\section{Other ESRRG regulatory miRNAs}

Several other miRNAs have been implicated in placental dysfunction by regulating proliferation, invasion, or invasion of trophoblastic-like cell lines, and by reducing ESRRG expression in other cell lines, these include miR378a-5p, miR-424, miR-377, and miR-204-5p (Eichner etal.2010, Chengetal.2018,Zouetal.2019).miR-378a-5p inhibits both mRNA and protein levels of ESRRG in the breast cancer cell line, BT-474 (Eichner et al. 2010); it also enhances the invasion and migration of HTR8/ SVneo cells and reduces BeWo cell differentiation (Luo et al. 2012, Nadeem et al. 2014). miR-424 expression was increased in FGR placentas (Huang et al. 2013) and miR-424 overexpression inhibited protein expression of

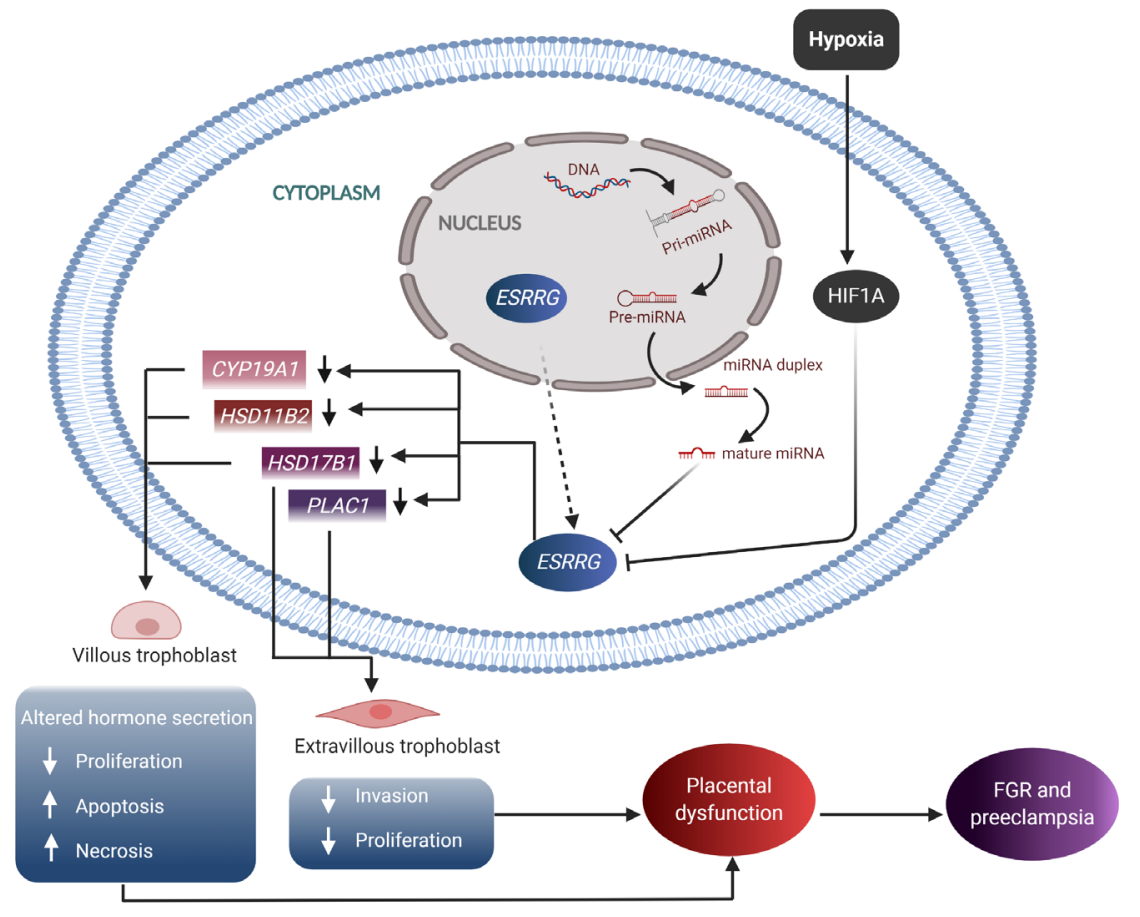

Figure 3 Proposed mechanism by which placental ESRRG expression and function is altered in pregnancies complicated by FGR and preeclampsia. The hypoxic environment of the maternofetal interface in FGR results in upregulation and activation of HIF1A in the placenta, resulting in inhibition of ESRRG expression. The expression of several miRNAs is upregulated in FGR and we propose that amongst these are key ESRRG regulatory miRNAs. Binding of these miRNAs to the 3'UTR of ESRRG results in mRNA degradation and inhibition of ESRRG protein translation. This leads to reduced expression of genes downstream of ESRRG, including CYP19A1, HSD 17B1, HSD11B2 and PLAC1. These downstream genes play an important role in placental hormone production and regulating different aspects of cytotrophoblast function, including villous cytotrophoblast proliferation and extravillous trophoblast invasion. 
ESRRG in HTR/8SVneo cells. However, this study did not identify a regulatory relationship between miR-424 and the 3'UTR of ESRRG, thus more in-depth studies of miR-424 are required in the future (Zou et al. 2019).

miR-377 is more highly expressed in human term placentas compared with first-trimester placentas, and overexpression of miR-377 in the first-trimester placental explants reduced cytotrophoblast proliferation (Farrokhnia et al. 2014). Furthermore, miR-377 inhibits the expression levels of SIRT1 in human retinal endothelial cells; taking into account the reported interaction between ESRRG and SIRT1 in the human placenta, miR-377 may also regulate ESRRG expression (Cui et al. 2019). As overexpression of miR-204-5p reduced the invasion of BeWo cells and JEG3 cells (Yu et al. 2015), and miR-204-5p overexpression reduced the differentiation of $\mathrm{C} 1 \mathrm{C} 12$ myoblast cells by directly targeting 3'UTR of ESRRG, this data suggest that a direct regulatory relationship may also exist between miR-204-5p and ESRRG in the placenta (Cheng et al. 2018). Since the above studies only used cell lines to assess trophoblast function, more data derived from primary placental models are needed; specifically those that focus on the relationship between individual miRNAs, ESRRG and its downstream effectors, and their roles in the etiology of FGR; these relationships have been summarized in Fig. 3.

Manipulation of the expression of miRNAs upstream of ESRRG may represent an additional approach to correct placental dysfunction; accumulating studies in vivo and in vitro indicate the possibility of developing an inverse agonist of ESRRG as a promising treatment for ESRRG-related anaplastic thyroid cancer, breast cancer, and type 2 diabetes (Kim et al. 2012, 2019, Vernier et al. 2020). Our group has demonstrated that targeted miRNA inhibitors can be used to selectively manipulate placental function: targeted inhibition of trophoblast miR-145 and miR-675 expression promoted cytotrophoblast proliferation in human first-trimester villous placental explants and increased fetal and placental weight when administered intravenously to pregnant mice (Beards et al. 2017). Therefore, exploring the regulatory pathway of ESRRG in the human placenta could inform the development of potential new therapeutic approaches for pregnancy complications involving placental dysfunction, like FGR or preeclampsia.

\section{Summary}

Even though many studies have focused on the pathogenesis of placental dysfunction underlying FGR and preeclampsia, the precise pathophysiological mechanisms and biochemical pathways in the placenta are still unclear, which limits options for therapeutic discovery, making a better understanding of the underpinning placental pathways a priority. The most obvious changes in the placenta in FGR and preeclampsia include abnormal trophoblast function, increased cell death, altered metabolism and nutrient transport, hypoxia and oxidative stress, and aberrant villous structure. Since ESRRG is highly expressed in the human normal term placenta, and it holds key roles in the regulation of cell invasion, differentiation, cellular energy homeostasis, hypoxic responses and metabolism, we argue that involvement of the ESRRG pathway in the placental dysfunction underlying FGR and preeclampsia is plausible, and thorough exploration may offer new therapeutic options. In support of this hypothesis, several studies have revealed significantly lower levels of ESRRG mRNA and protein in the human placenta in FGR, and ESRRG can regulate the invasion and proliferation of human trophoblast cell lines. Furthermore, additional evidence of disruption of both upstream regulators and downstream effectors of ESRRG provides evidence that the pathway is intact, and functions as expected in the human placenta. These data highlight that ESRRG may be involved in the development and pathogenesis of placental dysfunction by influencing trophoblast function and further studies of the regulation of this pathway are needed. By better understanding the intrinsic role of ESRRG as a regulator of trophoblast function, metabolism, and cell turnover, this in turn might provide new ideas for the treatment of placental dysfunction underpinning FGR and preeclampsia in the future.

\section{Declaration of interest}

The authors declare that there is no conflict of interest that could be perceived as prejudicing the impartiality of this review.

\section{Funding}

This student is supported by the joint scholarship of University of Manchester and Chinese government. A E P H is supported by Tommy's charity.

\section{Author contribution statement}

$\mathrm{Z} Z, \mathrm{~L} K \mathrm{H}, \mathrm{K}$, and A E P H conceived and designed the research. $Z Z$ drafted the manuscript. All authors read and approved the final manuscript.

\section{References}

ACOG 2019 American College of Obstetricians and Gynecologists Practice Bulletin No. 204: fetal growth restriction. Obstetrics and Gynecology 133 e97-e109. (https://doi.org/10.1097/AOG.0000000000003070)

Alaynick WA, Kondo RP, Xie W, He W, Dufour CR, Downes M, Jonker JW, Giles W, Naviaux RK, Giguere V et al. 2007 ERRgamma directs and maintains the transition to oxidative metabolism in the postnatal heart. Cell Metabolism 6 13-24. (https://doi.org/10.1016/j.cmet.2007.06.007)

Alaynick WA, Way JM, Wilson SA, Benson WG, Pei L, Downes M, Yu R, Jonker JW, Holt JA, Rajpal DK et al. 2010 ERRgamma regulates cardiac, 
gastric, and renal potassium homeostasis. Molecular Endocrinology 24 299-309. (https://doi.org/10.1210/me.2009-0114)

Alsat E, Wyplosz P, Malassine A, Guibourdenche J, Porquet D, Nessmann C \& Evain-Brion D 1996 Hypoxia impairs cell fusion and differentiation process in human cytotrophoblast, in vitro. Journal of Cellular Physiology 168 346-353. (https://doi.org/10.1002/(SICI)10974652(199608)168:2<346::AID-JCP13>3.0.CO;2-1)

Amat R, Planavila A, Chen SL, Iglesias R, Giralt M \& Villarroya F 2009 SIRT1 controls the transcription of the peroxisome proliferator-activated receptor-gamma co-activator-1alpha (PGC-1alpha) gene in skeletal muscle through the PGC-1alpha autoregulatory loop and interaction with MyoD. Journal of Biological Chemistry 284 21872-21880. (https:// doi.org/10.1074/jbc.M109.022749)

Anton L, Olarerin-George AO, Schwartz N, Srinivas S, Bastek J, Hogenesch JB \& Elovitz MA 2013 miR-210 inhibits trophoblast invasion and is a serum biomarker for preeclampsia. American Journal of Pathology 183 1437-1445. (https://doi.org/10.1016/j. ajpath.2013.07.021)

Arul Nambi Rajan K, Khater M, Soncin F, Pizzo D, Moretto-Zita M, Pham J, Stus O, lyer P, Tache V, Laurent LC et al. 2018 Sirtuin1 is required for proper trophoblast differentiation and placental development in mice. Placenta 62 1-8. (https://doi.org/10.1016/j.placenta.2017.12.002)

Atamer Y, Kocyigit Y, Yokus B, Atamer A \& Erden AC 2005 Lipid peroxidation, antioxidant defense, status of trace metals and leptin levels in preeclampsia. European Journal of Obstetrics, Gynecology, and Reproductive Biology 119 60-66. (https://doi.org/10.1016/j. ejogrb.2004.06.033)

Baek D, Villen J, Shin C, Camargo FD, Gygi SP \& Bartel DP 2008 The impact of microRNAs on protein output. Nature 455 64-71. (https://doi. org/10.1038/nature07242)

Beards F, Jones LE, Charnock J, Forbes K \& Harris LK 2017 Placental homing peptide-microRNA inhibitor conjugates for targeted enhancement of intrinsic placental growth signaling. Theranostics 7 2940-2955. (https:// doi.org/10.7150/thno.18845)

Benediktsson R, Lindsay RS, Noble J, Seckl JR \& Edwards CR 1993 Glucocorticoid exposure in utero: new model for adult hypertension. Lancet 341 339-341. (https://doi.org/10.1016/0140-6736(93)90138-7)

Bernstein IM, Horbar JD, Badger GJ, Ohlsson A \& Golan A 2000 Morbidity and mortality among very-low-birth-weight neonates with intrauterine growth restriction. The Vermont Oxford Network. American Journal of Obstetrics and Gynecology 182 198-206. (https://doi.org/10.1016/ s0002-9378(00)70513-8)

Bersinger NA \& Odegard RA 2005 Serum levels of macrophage colony stimulating, vascular endothelial, and placenta growth factor in relation to later clinical onset of pre-eclampsia and a small-for-gestational age birth. American Journal of Reproductive Immunology 54 77-83. (https:// doi.org/10.1111/j.1600-0897.2005.00290.x)

Biri A, Bozkurt N, Turp A, Kavutcu M, Himmetoglu O \& Durak I 2007 Role of oxidative stress in intrauterine growth restriction. Gynecologic and Obstetric Investigation 64 187-192. (https://doi.org/10.1159/000106488)

Bombail V, Gibson DA, Collins F, Macpherson S, Critchley HO \& Saunders PT 2010 A role for the orphan nuclear receptor estrogenrelated receptor alpha in endometrial stromal cell decidualization and expression of genes implicated in energy metabolism. Journal of Clinical Endocrinology and Metabolism 95 E224-E228. (https://doi.org/10.1210/ jc.2010-0154)

Brown MA, Magee LA, Kenny LC, Karumanchi SA, Mccarthy FP, Saito S, Hall DR, Warren CE, Adoyi G, Ishaku S et al. 2018 The hypertensive disorders of pregnancy: ISSHP classification, diagnosis and management recommendations for international practice. Pregnancy Hypertension 13 291-310. (https://doi.org/10.1016/j.preghy.2018.05.004)

Burton GJ \& Jauniaux E 2018 Pathophysiology of placental-derived fetal growth restriction. American Journal of Obstetrics and Gynecology 218 S745-S761. (https://doi.org/10.1016/j.ajog.2017.11.577)

Burton GJ, Charnock-Jones DS \& Jauniaux E 2009 Regulation of vascular growth and function in the human placenta. Reproduction 138 895-902. (https://doi.org/10.1530/REP-09-0092)

Chang WL, Wang H, Cui L, Peng NN, Fan X, Xue LQ \& Yang Q 2016 PLAC1 is involved in human trophoblast syncytialization. Reproductive Biology 16 218-224. (https://doi.org/10.1016/j.repbio.2016.07.001)

Chao EY, Collins JL, Gaillard S, Miller AB, Wang L, Orband-Miller LA, Nolte RT, Mcdonnell DP, Willson TM \& Zuercher WJ 2006 Structure- guided synthesis of tamoxifen analogs with improved selectivity for the orphan ERRgamma. Bioorganic and Medicinal Chemistry Letters 16 821-824. (https://doi.org/10.1016/j.bmcl.2005.11.030)

Cheng X, Du J, Shen L, Tan Z, Jiang D, Jiang A, Li Q, Tang G, Jiang Y, Wang J et al. 2018 MiR-204-5p regulates C2C12 myoblast differentiation by targeting MEF2C and ERRgamma. Biomedicine and Pharmacotherapy 101 528-535. (https://doi.org/10.1016/j.biopha.2018.02.096)

Chui A, Murthi P, Gunatillake T, Brennecke SP, Ignjatovic V, Monagle PT, Whitelock JM \& Said JM 2014 Altered decorin leads to disrupted endothelial cell function: a possible mechanism in the pathogenesis of fetal growth restriction? Placenta 35 596-605. (https://doi.org/10.1016/j. placenta.2014.05.009)

Corcoran J, Lacey H, Baker PN \& Wareing M 2008 Altered potassium channel expression in the human placental vasculature of pregnancies complicated by fetal growth restriction. Hypertension in Pregnancy 27 75-86. (https://doi.org/10.1080/10641950701826158)

Crispi F, Bijnens B, Figueras F, Bartrons J, Eixarch E, Le Noble F, Ahmed A \& Gratacos E 2010 Fetal growth restriction results in remodeled and less efficient hearts in children. Circulation 121 2427-2436. (https://doi. org/10.1161/CIRCULATIONAHA.110.937995)

Cui C, Li Y \& Liu Y 2019 Down-regulation of miR-377 suppresses high glucose and hypoxia-induced angiogenesis and inflammation in human retinal endothelial cells by direct up-regulation of target gene SIRT1. Human Cell 32 260-274. (https://doi.org/10.1007/s13577-01900240-w)

Curtis S, Jones CJ, Garrod A, Hulme CH \& Heazell AE 2013 Identification of autophagic vacuoles and regulators of autophagy in villous trophoblast from normal term pregnancies and in fetal growth restriction. Journal of Maternal-Fetal and Neonatal Medicine 26 339-346. (https://doi.org/10.3 109/14767058.2012.733764)

Deblois G, Hall JA, Perry MC, Laganiere J, Ghahremani M, Park M, Hallett M \& Giguere V 2009 Genome-wide identification of direct target genes implicates estrogen-related receptor alpha as a determinant of breast cancer heterogeneity. Cancer Research 69 6149-6157. (https:// doi.org/10.1158/0008-5472.CAN-09-1251)

Diamant YZ, Mayorek N, Neumann S \& Shafrir E 1975 Enzymes of glucose and fatty acid metabolism in early and term human placenta. American Journal of Obstetrics and Gynecology 121 58-61. (https://doi. org/10.1016/0002-9378(75)90975-8)

Dufour CR, Wilson BJ, Huss JM, Kelly DP, Alaynick WA, Downes M, Evans RM, Blanchette M \& Giguere V 2007 Genome-wide orchestration of cardiac functions by the orphan nuclear receptors ERRalpha and gamma. Cell Metabolism 5 345-356. (https://doi.org/10.1016/j. cmet.2007.03.007)

Eichner LJ, Perry MC, Dufour CR, Bertos N, Park M, St-Pierre J \& Giguere V 2010 miR-378(*) mediates metabolic shift in breast cancer cells via the PGC-1beta/ERRgamma transcriptional pathway. Cell Metabolism 12 352-361. (https://doi.org/10.1016/j.cmet.2010.09.002)

Fan W, He N, Lin CS, Wei Z, Hah N, Waizenegger W, He MX, Liddle C, Yu RT, Atkins AR et al. 2018 ERRgamma promotes angiogenesis, mitochondrial biogenesis, and oxidative remodeling in PGC1alpha/betadeficient muscle. Cell Reports 22 2521-2529. (https://doi.org/10.1016/j. celrep.2018.02.047)

Farrokhnia F, Aplin JD, Westwood M \& Forbes K 2014 MicroRNA regulation of mitogenic signaling networks in the human placenta. Journal of Biological Chemistry 289 30404-30416. (https://doi.org/10.1074/jbc. M114.587295)

Fournet-Dulguerov N, Maclusky NJ, Leranth CZ, Todd R, Mendelson CR, Simpson ER \& Naftolin F 1987 Immunohistochemical localization of aromatase cytochrome P-450 and estradiol dehydrogenase in the syncytiotrophoblast of the human placenta. Journal of Clinical Endocrinology and Metabolism 65 757-764. (https://doi.org/10.1210/ jcem-65-4-757)

Friedman RC, Farh KK, Burge CB \& Bartel DP 2009 Most mammalian mRNAs are conserved targets of microRNAs. Genome Research 19 92-105. (https://doi.org/10.1101/gr.082701.108)

Gao T, Deng M \& Wang Q 2018 MiRNA-320a inhibits trophoblast cell invasion by targeting estrogen-related receptor-gamma. Journal of Obstetrics and Gynaecology Research 44 756-763. (https://doi. org/10.1111/jog.13560)

Gardosi J, Kady SM, Mcgeown P, Francis A \& Tonks A 2005 Classification of stillbirth by relevant condition at death (ReCoDe): population 
based cohort study. BMJ 331 1113-1117. (https://doi.org/10.1136/ bmj.38629.587639.7C)

Genbacev O, Joslin R, Damsky CH, Polliotti BM \& Fisher SJ 1996 Hypoxia alters early gestation human cytotrophoblast differentiation/invasion in vitro and models the placental defects that occur in preeclampsia. Journal of Clinical Investigation 97 540-550. (https://doi.org/10.1172/ JCl118447)

Gerhart-Hines Z, Rodgers JT, Bare O, Lerin C, Kim SH, Mostoslavsky R, Alt FW, Wu Z \& Puigserver P 2007 Metabolic control of muscle mitochondrial function and fatty acid oxidation through SIRT1/PGC1alpha. EMBO Journal 26 1913-1923. (https://doi.org/10.1038/ sj.emboj.7601633)

Giguere V 1999 Orphan nuclear receptors: from gene to function. Endocrine Reviews 20 689-725. (https://doi.org/10.1210/edrv.20.5.0378)

Giguere V 2008 Transcriptional control of energy homeostasis by the estrogen-related receptors. Endocrine Reviews 29 677-696. (https://doi. org/10.1210/er.2008-0017)

Giguere V, Yang N, Segui P \& Evans RM 1988 Identification of a new class of steroid hormone receptors. Nature 331 91-94. (https://doi. org/10.1038/331091a0)

Greschik H, Wurtz JM, Sanglier S, Bourguet W, Van Dorsselaer A, Moras D \& Renaud JP 2002 Structural and functional evidence for ligand-independent transcriptional activation by the estrogen-related receptor 3. Molecular Cell 9 303-313. (https://doi.org/10.1016/s10972765(02)00444-6)

Hardy DB \& Yang K 2002 The expression of 11 beta-hydroxysteroid dehydrogenase type 2 is induced during trophoblast differentiation: effects of hypoxia. Journal of Clinical Endocrinology and Metabolism 87 3696-3701. (https://doi.org/10.1210/jcem.87.8.8720)

Heard DJ, Norby PL, Holloway J \& Vissing H 2000 Human ERRgamma, a third member of the estrogen receptor-related receptor (ERR) subfamily of orphan nuclear receptors: tissue-specific isoforms are expressed during development and in the adult. Molecular Endocrinology $\mathbf{1 4}$ 382-392. (https://doi.org/10.1210/mend.14.3.0431)

Heazell AE, Moll SJ, Jones CJ, Baker PN \& Crocker IP 2007 Formation of syncytial knots is increased by hyperoxia, hypoxia and reactive oxygen species. Placenta 28 (Supplement A) S33-S40. (https://doi.org/10.1016/j. placenta.2006.10.007)

Heazell AE, Lacey HA, Jones CJ, Huppertz B, Baker PN \& Crocker IP 2008 Effects of oxygen on cell turnover and expression of regulators of apoptosis in human placental trophoblast. Placenta 29 175-186. (https:// doi.org/10.1016/j.placenta.2007.11.002)

Heazell AE, Sharp AN, Baker PN \& Crocker IP 2011 Intra-uterine growth restriction is associated with increased apoptosis and altered expression of proteins in the p53 pathway in villous trophoblast. Apoptosis $\mathbf{1 6}$ 135-144. (https://doi.org/10.1007/s10495-010-0551-3)

Hitschold T, Weiss E, Beck T, Hunterfering H \& Berle P 1993 Low target birth weight or growth retardation? Umbilical Doppler flow velocity waveforms and histometric analysis of fetoplacental vascular tree. American Journal of Obstetrics and Gynecology 168 1260-1264. (https://doi.org/10.1016/0002-9378(93)90377-u)

Homan A, Guan H, Hardy DB, Gratton RJ \& Yang K 2006 Hypoxia blocks 11 beta-hydroxysteroid dehydrogenase type 2 induction in human trophoblast cells during differentiation by a time-dependent mechanism that involves both translation and transcription. Placenta 27 832-840. (https://doi.org/10.1016/j.placenta.2005.09.006)

Hromadnikova I, Kotlabova K, Ondrackova M, Pirkova P, Kestlerova A, Novotna V, Hympanova L \& Krofta L 2015 Expression profile of C19MC microRNAs in placental tissue in pregnancy-related complications. DNA and Cell Biology 34 437-457. (https://doi.org/10.1089/ dna.2014.2687)

Huang L, Shen Z, Xu Q, Huang X, Chen Q \& Li D 2013 Increased levels of microRNA-424 are associated with the pathogenesis of fetal growth restriction. Placenta 34 624-627. (https://doi.org/10.1016/j. placenta.2013.04.009)

Hung TH \& Burton GJ 2006 Hypoxia and reoxygenation: a possible mechanism for placental oxidative stress in preeclampsia. Taiwanese Journal of Obstetrics and Gynecology 45 189-200. (https://doi. org/10.1016/S1028-4559(09)60224-2)

Huppertz B 2011 Trophoblast differentiation, fetal growth restriction and preeclampsia. Pregnancy Hypertension 1 79-86. (https://doi. org/10.1016/j.preghy.2010.10.003)
Huppunen J \& Aarnisalo P 2004 Dimerization modulates the activity of the orphan nuclear receptor ERRgamma. Biochemical and Biophysical Research Communications 314 964-970. (https://doi.org/10.1016/j. bbrc.2003.12.194)

Huss JM, Kopp RP \& Kelly DP 2002 Peroxisome proliferator-activated receptor coactivator-1alpha (PGC-1alpha) coactivates the cardiacenriched nuclear receptors estrogen-related receptor-alpha and -gamma. Identification of novel leucine-rich interaction motif within PGC1alpha. Journal of Biological Chemistry 277 40265-40274. (https://doi. org/10.1074/jbc.M206324200)

Iniguez-Lluhi JA \& Pearce D 2000 A common motif within the negative regulatory regions of multiple factors inhibits their transcriptional synergy. Molecular and Cellular Biology 20 6040-6050. (https://doi. org/10.1128/mcb.20.16.6040-6050.2000)

Ishibashi O, Ohkuchi A, Ali MM, Kurashina R, Luo SS, Ishikawa T, Takizawa T, Hirashima C, Takahashi K, Migita M et al. 2012 Hydroxysteroid (17-beta) dehydrogenase 1 is dysregulated by miR-210 and miR-518c that are aberrantly expressed in preeclamptic placentas: a novel marker for predicting preeclampsia. Hypertension 59 265-273. (https://doi.org/10.1161/HYPERTENSIONAHA.111.180232)

Jackson MR, Walsh AJ, Morrow RJ, Mullen JB, Lye SJ \& Ritchie JW 1995 Reduced placental villous tree elaboration in small-for-gestational-age pregnancies: relationship with umbilical artery Doppler waveforms. American Journal of Obstetrics and Gynecology 172 518-525. (https:// doi.org/10.1016/0002-9378(95)90566-9)

Johnston SD, Liu X, Zuo F, Eisenbraun TL, Wiley SR, Kraus RJ \& Mertz JE 1997 Estrogen-related receptor alpha 1 functionally binds as a monomer to extended half-site sequences including ones contained within estrogen-response elements. Molecular Endocrinology 11 342-352. (https://doi.org/10.1210/mend.11.3.9897)

Jones CJ \& Fox H 1991 Ultrastructure of the normal human placenta. Electron Microscopy Reviews 4 129-178. (https://doi.org/10.1016/08920354(91)90019-9)

Kallen J, Schlaeppi JM, Bitsch F, Filipuzzi I, Schilb A, Riou V, Graham A, Strauss A, Geiser M \& Fournier B 2004 Evidence for ligand-independent transcriptional activation of the human estrogen-related receptor alpha (ERRalpha): crystal structure of ERRalpha ligand binding domain in complex with peroxisome proliferator-activated receptor coactivator1alpha. Journal of Biological Chemistry 279 49330-49337. (https://doi. org/10.1074/jbc.M407999200)

Kamarajugadda S, Stemboroski L, Cai Q, Simpson NE, Nayak S, Tan M \& Lu J 2012 Glucose oxidation modulates anoikis and tumor metastasis. Molecular and Cellular Biology 32 1893-1907. (https://doi.org/10.1128/ MCB.06248-11)

Kamat A, Alcorn JL, Kunczt C \& Mendelson CR 1998 Characterization of the regulatory regions of the human aromatase (P450arom) gene involved in placenta-specific expression. Molecular Endocrinology 12 1764-1777. (https://doi.org/10.1210/mend.12.11.0190)

Kim DK, Ryu D, Koh M, Lee MW, Lim D, Kim MJ, Kim YH, Cho WJ, Lee CH, Park SB et al. 2012 Orphan nuclear receptor estrogen-related receptor gamma (ERRgamma) is key regulator of hepatic gluconeogenesis. Journal of Biological Chemistry 287 21628-21639. (https://doi.org/10.1074/jbc. M111.315168)

Kim J, Song J, Ji HD, Yoo EK, Lee JE, Lee SB, Oh JM, Lee S, Hwang JS, Yoon H et al. 2019 Discovery of potent, selective, and orally bioavailable estrogen-related receptor-gamma inverse agonists to restore the sodium iodide symporter function in anaplastic thyroid cancer. Journal of Medicinal Chemistry 62 1837-1858. (https://doi.org/10.1021/acs. jmedchem.8b01296)

Kimura C, Watanabe K, Iwasaki A, Mori T, Matsushita H, Shinohara K \& Wakatsuki A 2013 The severity of hypoxic changes and oxidative DNA damage in the placenta of early-onset preeclamptic women and fetal growth restriction. Journal of Maternal-Fetal and Neonatal Medicine $\mathbf{2 6}$ 491-496. (https://doi.org/10.3109/14767058.2012.733766)

Kingdom J, Huppertz B, Seaward G \& Kaufmann P 2000 Development of the placental villous tree and its consequences for fetal growth. European Journal of Obstetrics, Gynecology, and Reproductive Biology 92 35-43. (https://doi.org/10.1016/s0301-2115(00)00423-1)

Krebs C, Macara LM, Leiser R, Bowman AW, Greer IA \& Kingdom JC 1996 Intrauterine growth restriction with absent end-diastolic flow velocity in the umbilical artery is associated with maldevelopment of the placental terminal villous tree. American Journal of Obstetrics 
and Gynecology 175 1534-1542. (https://doi.org/10.1016/s00029378(96)70103-5)

Kubo M, Ijichi N, Ikeda K, Horie-Inoue K, Takeda S \& Inoue S 2009 Modulation of adipogenesis-related gene expression by estrogenrelated receptor gamma during adipocytic differentiation. Biochimica et Biophysica Acta $\mathbf{1 7 8 9}$ 71-77. (https://doi.org/10.1016/j. bbagrm.2008.08.012)

Kumar P \& Mendelson CR 2011 Estrogen-related receptor gamma (ERRgamma) mediates oxygen-dependent induction of aromatase (CYP19) gene expression during human trophoblast differentiation. Molecular Endocrinology 25 1513-1526. (https://doi.org/10.1210/ me.2011-1012)

Lappas M, Mitton A, Lim R, Barker G, Riley C \& Permezel M 2011 SIRT1 is a novel regulator of key pathways of human labor. Biology of Reproduction 84 167-178. (https://doi.org/10.1095/biolreprod.110.086983)

Leduc L, Levy E, Bouity-Voubou M \& Delvin E 2010 Fetal programming of atherosclerosis: possible role of the mitochondria. European Journal of Obstetrics, Gynecology, and Reproductive Biology 149 127-130. (https://doi.org/10.1016/j.ejogrb.2009.12.005)

Lee JH, Kim EJ, Kim DK, Lee JM, Park SB, Lee IK, Harris RA, Lee MO \& Choi HS 2012 Hypoxia induces PDK4 gene expression through induction of the orphan nuclear receptor ERRgamma. PLOS ONE 7 e46324. (https://doi.org/10.1371/journal.pone.0046324)

Leibiger IB \& Berggren PO 2006 Sirt1: a metabolic master switch that modulates lifespan. Nature Medicine 12 34-36; discussion 36. (https:// doi.org/10.1038/nm0106-34)

Levy R, Smith SD, Chandler K, Sadovsky Y \& Nelson DM 2000 Apoptosis in human cultured trophoblasts is enhanced by hypoxia and diminished by epidermal growth factor. American Journal of Physiology: Cell Physiology 278 C982-C988. (https://doi.org/10.1152/ajpcell.2000.278.5.C982)

Li Q, Pan Z, Wang X, Gao Z, Ren C \& Yang W 2014 miR-125b-1-3p inhibits trophoblast cell invasion by targeting sphingosine-1-phosphate receptor 1 in preeclampsia. Biochemical and Biophysical Research Communications 453 57-63. (https://doi.org/10.1016/j.bbrc.2014.09.059)

Liu D, Zhang Z \& Teng CT 2005 Estrogen-related receptor-gamma and peroxisome proliferator-activated receptor-gamma coactivator-1alpha regulate estrogen-related receptor-alpha gene expression via a conserved multi-hormone response element. Journal of Molecular Endocrinology 34 473-487. (https://doi.org/10.1677/jme.1.01586)

Liu RH, Meng Q, Shi YP \& Xu HS 2018 Regulatory role of microRNA-320a in the proliferation, migration, invasion, and apoptosis of trophoblasts and endothelial cells by targeting estrogen-related receptor gamma. Journal of Cellular Physiology 234 682-691. (https://doi.org/10.1002/ jcp.26842)

Luo L, Ye G, Nadeem L, Fu G, Yang BB, Honarparvar E, Dunk C, Lye S \& Peng C 2012 MicroRNA-378a-5p promotes trophoblast cell survival, migration and invasion by targeting nodal. Journal of Cell Science $\mathbf{1 2 5}$ 3124-3132. (https://doi.org/10.1242/jcs.096412)

Luo Y, Kumar P \& Mendelson CR 2013 Estrogen-related receptor gamma (ERRgamma) regulates oxygen-dependent expression of voltage-gated potassium $(\mathrm{K}+)$ channels and tissue kallikrein during human trophoblast differentiation. Molecular Endocrinology 27 940-952. (https://doi. org/10.1210/me.2013-1038)

Luo Y, Kumar P, Chen CC, Latham J, Wang L, Tudela C, Alexander JM, Shelton JM, Mckown L \& Mendelson CR 2014 Estrogen-related receptor gamma serves a role in blood pressure homeostasis during pregnancy. Molecular Endocrinology 28 965-975. (https://doi.org/10.1210/ me.2014-1003)

Luo C, Balsa E, Thomas A, Hatting M, Jedrychowski M, Gygi SP, Widlund HR \& Puigserver P 2017 ERRalpha maintains mitochondrial oxidative metabolism and constitutes an actionable target in PGC1alpha-elevated melanomas. Molecular Cancer Research 15 1366-1375. (https://doi. org/10.1158/1541-7786.MCR-17-0143)

Macara L, Kingdom JC, Kaufmann P, Kohnen G, Hair J, More IA, Lyall F \& Greer IA 1996 Structural analysis of placental terminal villi from growth-restricted pregnancies with abnormal umbilical artery Doppler waveforms. Placenta 17 37-48. (https://doi.org/10.1016/s01434004(05)80642-3)

Malek A, Miller RK, Mattison DR, Kennedy S, Panigel M, Di Sant'Agnese PA \& Jessee L 1996 Energy charge monitoring via magnetic resonance spectroscopy $31 \mathrm{P}$ in the perfused human placenta: effects of cadmium, dinitrophenol and iodoacetate. Placenta 17 495-506. (https://doi. org/10.1016/s0143-4004(96)90032-6)

Matsakas A, Yadav V, Lorca S, Evans RM \& Narkar VA 2012 Revascularization of ischemic skeletal muscle by estrogen-related receptor-gamma. Circulation Research 110 1087-1096. (https://doi. org/10.1161/CIRCRESAHA.112.266478)

McBurney MW, Yang X, Jardine K, Hixon M, Boekelheide K, Webb JR, Lansdorp PM \& Lemieux M 2003 The mammalian SIR2alpha protein has a role in embryogenesis and gametogenesis. Molecular and Cellular Biology 23 38-54. (https://doi.org/10.1128/mcb.23.1.38-54.2003)

McTernan CL, Draper N, Nicholson H, Chalder SM, Driver P, Hewison M, Kilby MD \& Stewart PM 2001 Reduced placental 11 beta-hydroxysteroid dehydrogenase type 2 mRNA levels in human pregnancies complicated by intrauterine growth restriction: an analysis of possible mechanisms. Journal of Clinical Endocrinology and Metabolism 86 4979-4983. (https://doi.org/10.1210/jcem.86.10.7893)

Miao M, Yuan W, Zhu G, He X \& Li D K 2011 In utero exposure to bisphenol-A and its effect on birth weight of offspring. Reproductive Toxicology 32 64-8. (https://doi.org/10.1016/j.reprotox.2011.03.002)

Misra J, Kim DK \& Choi HS 2017 ERRgamma: a junior orphan with a senior role in metabolism. Trends in Endocrinology and Metabolism 28 261-272. (https://doi.org/10.1016/j.tem.2016.12.005)

Mistry HD, Mccallum LA, Kurlak LO, Greenwood IA, Broughton Pipkin F \& Tribe RM 2011 Novel expression and regulation of voltagedependent potassium channels in placentas from women with preeclampsia. Hypertension 58 497-504. (https://doi.org/10.1161/ HYPERTENSIONAHA.111.173740)

Nadeem U, Ye G, Salem M \& Peng C 2014 MicroRNA-378a-5p targets cyclin G2 to inhibit fusion and differentiation in BeWo cells. Biology of Reproduction 91 76. (https://doi.org/10.1095/ biolreprod.114.119065)

Ohkuchi A, Ishibashi O, Hirashima C, Takahashi K, Matsubara S, Takizawa T \& Suzuki M 2012 Plasma level of hydroxysteroid (17-beta) dehydrogenase 1 in the second trimester is an independent risk factor for predicting preeclampsia after adjusting for the effects of mean blood pressure, bilateral notching and plasma level of soluble fms-like tyrosine kinase 1/placental growth factor ratio. Hypertension Research 35 1152-1158. (https://doi.org/10.1038/hr.2012.109)

Okada H, Tokunaga T, Liu X, Takayanagi S, Matsushima A \& Shimohigashi Y 2008 Direct evidence revealing structural elements essential for the high binding ability of bisphenol A to human estrogen-related receptorgamma. Environmental Health Perspectives 116 32-38. (https://doi. org/10.1289/ehp.10587)

Patel S, Kilburn B, Imudia A, Armant DR \& Skafar DF 2015 Estradiol elicits proapoptotic and antiproliferative effects in human trophoblast cells. Biology of Reproduction 93 74. (https://doi.org/10.1095/ biolreprod.115.129114)

Payne AH \& Hales DB 2004 Overview of steroidogenic enzymes in the pathway from cholesterol to active steroid hormones. Endocrine Reviews 25 947-970. (https://doi.org/10.1210/er.2003-0030)

Pels A, Knaven OC, Wijnberg-Williams BJ, Eijsermans MJC, Mulder-De Tollenaer SM, Aarnoudse-Moens CSH, Koopman-Esseboom C, Van Eyck J, Derks JB, Ganzevoort W et al. 2019 Neurodevelopmental outcomes at five years after early-onset fetal growth restriction: analyses in a Dutch subgroup participating in a European management trial. European Journal of Obstetrics, Gynecology, and Reproductive Biology 234 63-70. (https://doi.org/10.1016/j.ejogrb.2018.12.041)

Pepe GJ, Burch MG \& Albrecht ED 1999 Expression of the 11 betahydroxysteroid dehydrogenase types 1 and 2 proteins in human and baboon placental syncytiotrophoblast. Placenta 20 575-582. (https:// doi.org/10.1053/plac.1999.0416)

Pijnenborg R, Bland JM, Robertson WB \& Brosens I 1983 Uteroplacental arterial changes related to interstitial trophoblast migration in early human pregnancy. Placenta 4 397-413. (https://doi.org/10.1016/s01434004(83)80043-5)

Poidatz D, Dos Santos E, Brule A, De Mazancourt P \& Dieudonne MN 2012 Estrogen-related receptor gamma modulates energy metabolism target genes in human trophoblast. Placenta 33 688-695. (https://doi. org/10.1016/j.placenta.2012.06.002)

Poidatz D, Dos Santos E, Duval F, Moindjie H, Serazin V, Vialard F, De Mazancourt P \& Dieudonne MN 2015 Involvement of estrogen-related 
receptor-gamma and mitochondrial content in intrauterine growth restriction and preeclampsia. Fertility and Sterility 104 483-490. (https:// doi.org/10.1016/j.fertnstert.2015.05.005)

Rajakumar A, Brandon HM, Daftary A, Ness R \& Conrad KP 2004 Evidence for the functional activity of hypoxia-inducible transcription factors overexpressed in preeclamptic placentae. Placenta 25 763-769. (https://doi.org/10.1016/j.placenta.2004.02.011)

Ramirez-Velez R, Correa-Bautista JE, Villa-Gonzalez E, MartinezTorres J, Hackney AC \& Garcia-Hermoso A 2017 Effects of preterm birth and fetal growth retardation on life-course cardiovascular risk factors among schoolchildren from Colombia: the FUPRECOL study. Early Human Development 106-107 53-58. (https://doi.org/10.1016/j. earlhumdev.2017.02.001)

Redman CW 1991 Current topic: pre-eclampsia and the placenta. Placenta 12 301-308. (https://doi.org/10.1016/0143-4004(91)90339-h)

Robb KP, Cotechini T, Allaire C, Sperou A \& Graham CH 2017 Inflammation-induced fetal growth restriction in rats is associated with increased placental HIF-1alpha accumulation. PLOS ONE 12 e0175805. (https://doi.org/10.1371/journal.pone.0175805)

Roberts DJ \& Post MD 2008 The placenta in pre-eclampsia and intrauterine growth restriction. Journal of Clinical Pathology 61 1254-1260. (https:// doi.org/10.1136/jcp.2008.055236)

Schulz H 1991 Beta oxidation of fatty acids. Biochimica et Biophysica Acta 1081 109-120. (https://doi.org/10.1016/0005-2760(91)90015-A)

Sifakis S, Androutsopoulos VP, Pontikaki A, Velegrakis A, Papaioannou GI, Koukoura O, Spandidos DA \& Papantoniou N 2018 Placental expression of PAPPA, PAPPA-2 and PLAC-1 in pregnacies is associated with FGR. Molecular Medicine Reports 17 6435-6440. (https://doi.org/10.3892/ mmr.2018.8721)

Souza JP, Gulmezoglu AM, Vogel J, Carroli G, Lumbiganon P, Qureshi Z, Costa MJ, Fawole B, Mugerwa Y, Nafiou I et al. 2013 Moving beyond essential interventions for reduction of maternal mortality (the WHO Multicountry Survey on Maternal and Newborn Health): a crosssectional study. Lancet 381 1747-1755. (https://doi.org/10.1016/S01406736(13)60686-8)

Spinillo A, Gardella B, Adamo L, Muscettola G, Fiandrino G \& Cesari S 2019 Pathologic placental lesions in early and late fetal growth restriction. Acta Obstetricia and Gynecologica Scandinavica 98 1585-1594. (https://doi.org/10.1111/aogs.13699)

Struwe E, Berzl GM, Schild RL, Beckmann MW, Dorr HG, Rascher W \& Dotsch J 2007 Simultaneously reduced gene expression of cortisol-activating and cortisol-inactivating enzymes in placentas of small-for-gestational-age neonates. American Journal of Obstetrics and Gynecology 197 43.e1-43.e6. (https://doi.org/10.1016/j. ajog.2007.02.012)

Sugden MC \& Holness MJ 2003 Recent advances in mechanisms regulating glucose oxidation at the level of the pyruvate dehydrogenase complex by PDKs. American Journal of Physiology. Endocrinology and Metabolism 284 E855-E862. (https://doi.org/10.1152/ajpendo.00526.2002)

Takagi Y, Nikaido T, Toki T, Kita N, Kanai M, Ashida T, Ohira S \& Konishi I 2004 Levels of oxidative stress and redox-related molecules in the placenta in preeclampsia and fetal growth restriction. Virchows Archiv 444 49-55. (https://doi.org/10.1007/s00428-003-0903-2)

Takayanagi S, Tokunaga T, Liu X, Okada H, Matsushima A \& Shimohigashi Y 2006 Endocrine disruptor bisphenol A strongly binds to human estrogen-related receptor gamma (ERRgamma) with high constitutive activity. Toxicology Letters 167 95-105. (https://doi.org/10.1016/j. toxlet.2006.08.012)

Takeda Y, Liu X, Sumiyoshi M, Matsushima A, Shimohigashi M \& Shimohigashi Y 2009 Placenta expressing the greatest quantity of bisphenol A receptor ERR\{gamma\} among the human reproductive tissues: predominant expression of type-1 ERRgamma isoform. Journal of Biochemistry 146 113-122. (https://doi.org/10.1093/jb/mvp049)

Torrano V, Valcarcel-Jimenez L, Cortazar AR, Liu X, Urosevic J, CastilloMartin M, Fernandez-Ruiz S, Morciano G, Caro-Maldonado A, Guiu M et al. 2016 The metabolic co-regulator PGC1alpha suppresses prostate cancer metastasis. Nature Cell Biology 18 645-656. (https://doi. org/10.1038/ncb3357)

Tremblay GB, Bergeron D \& Giguere V 2001a 4-Hydroxytamoxifen is an isoform-specific inhibitor of orphan estrogen-receptor-related (ERR) nuclear receptors beta and gamma. Endocrinology 142 4572-4575. (https://doi.org/10.1210/endo.142.10.8528)

Tremblay GB, Kunath T, Bergeron D, Lapointe L, Champigny C, Bader JA, Rossant J \& Giguere V 2001b Diethylstilbestrol regulates trophoblast stem cell differentiation as a ligand of orphan nuclear receptor ERR beta. Genes and Development 15 833-838. (https://doi.org/10.1101/ gad.873401)

Tremblay AM, Wilson BJ, Yang XJ \& Giguere V 2008 Phosphorylationdependent SUMOylation regulates estrogen-related receptor-alpha and -gamma transcriptional activity through a synergy control motif. Molecular Endocrinology 22 570-584. (https://doi.org/10.1210/ me.2007-0357)

Troisi J, Mikelson C, Richards S, Symes S, Adair D, Zullo F \& Guida M 2014 Placental concentrations of bisphenol A and birth weight from births in the Southeastern U.S. Placenta 35 947-952. (https://doi.org/10.1016/j. placenta.2014.08.091)

Tzschoppe A, Struwe E, Blessing H, Fahlbusch F, Liebhaber G, Dorr HG, Rauh M, Rascher W, Goecke TW, Schild RL et al. 2009 Placental 11 beta-HSD2 gene expression at birth is inversely correlated with growth velocity in the first year of life after intrauterine growth restriction. Pediatric Research 65 647-653. (https://doi.org/10.1203/ PDR.0b013e31819e7337)

Vanacker JM, Pettersson K, Gustafsson JA \& Laudet V 1999 Transcriptional targets shared by estrogen receptor-related receptors (ERRs) and estrogen receptor (ER) alpha, but not by ERbeta. EMBO Journal 18 4270-4279. (https://doi.org/10.1093/emboj/18.15.4270)

Vernier M, Dufour CR, Mcguirk S, Scholtes C, Li X, Bourmeau G, Kuasne H, Park M, St-Pierre J, Audet-Walsh E et al. 2020 Estrogenrelated receptors are targetable ROS sensors. Genes and Development 34 544-559. (https://doi.org/10.1101/gad.330746.119)

Wilson BJ, Tremblay AM, Deblois G, Sylvain-Drolet G \& Giguere V 2010 An acetylation switch modulates the transcriptional activity of estrogenrelated receptor alpha. Molecular Endocrinology 24 1349-1358. (https:// doi.org/10.1210/me.2009-0441)

Xie YB, Park JH, Kim DK, Hwang JH, Oh S, Park SB, Shong M, Lee IK \& Choi HS 2009 Transcriptional corepressor SMILE recruits SIRT1 to inhibit nuclear receptor estrogen receptor-related receptor gamma transactivation. Journal of Biological Chemistry $28428762-28774$. (https://doi.org/10.1074/jbc.M109.034165)

Yang N, Shigeta H, Shi H \& Teng CT 1996 Estrogen-related receptor, hERR1, modulates estrogen receptor-mediated response of human lactoferrin gene promoter. Journal of Biological Chemistry 271 5795-5804. (https:// doi.org/10.1074/jbc.271.10.5795)

Ylikorkala A, Rossi DJ, Korsisaari N, Luukko K, Alitalo K, Henkemeyer M \& Makela TP 2001 Vascular abnormalities and deregulation of VEGF in LKB1-deficient mice. Science 293 1323-1326. (https://doi.org/10.1126/ science.1062074)

Yu Y, Wang L, Liu T \& Guan H 2015 MicroRNA-204 suppresses trophoblastlike cell invasion by targeting matrix metalloproteinase-9. Biochemical and Biophysical Research Communications 463 285-291. (https://doi. org/10.1016/j.bbrc.2015.05.052)

Yung HW, Calabrese S, Hynx D, Hemmings BA, Cetin I, CharnockJones DS \& Burton GJ 2008 Evidence of placental translation inhibition and endoplasmic reticulum stress in the etiology of human intrauterine growth restriction. American Journal of Pathology 173 451-462. (https:// doi.org/10.2353/ajpath.2008.071193)

Yung HW, Colleoni F, Dommett E, Cindrova-Davies T, Kingdom J, Murray AJ \& Burton GJ 2019 Noncanonical mitochondrial unfolded protein response impairs placental oxidative phosphorylation in earlyonset preeclampsia. PNAS 116 18109-18118. (https://doi.org/10.1073/ pnas.1907548116)

Zhang Y, Ma K, Sadana P, Chowdhury F, Gaillard S, Wang F, McDonnell DP, Unterman TG, Elam MB \& Park EA 2006a Estrogen-related receptors stimulate pyruvate dehydrogenase kinase isoform 4 gene expression. Journal of Biological Chemistry 281 39897-39906. (https://doi. org/10.1074/jbc.M608657200)

Zhang Z, Chen K, Shih JC \& Teng CT 2006b Estrogen-related receptorsstimulated monoamine oxidase B promoter activity is down-regulated by estrogen receptors. Molecular Endocrinology 20 1547-1561. (https:// doi.org/10.1210/me.2005-0252) 
Zhang Y, Diao Z, Su L, Sun H, Li R, Cui H \& Hu Y 2010 MicroRNA-155 contributes to preeclampsia by down-regulating CYR61. American Journal of Obstetrics and Gynecology 202 466.e1-466.e7. (https://doi. org/10.1016/j.ajog.2010.01.057)

Zhu H, Huang L, He Z, Zou Z \& Luo Y 2018a Estrogen-related receptor gamma regulates expression of 17 beta-hydroxysteroid dehydrogenase type 1 in fetal growth restriction. Placenta 67 38-44. (https://doi. org/10.1016/j.placenta.2018.05.012)

Zhu P, Wang W, Zuo R \& Sun K 2018b Mechanisms for establishment of the placental glucocorticoid barrier, a guard for life. Cellular and Molecular Life Sciences 76 13-26. (https://doi.org/10.1007/s00018018-2918-5)
Zou Z, He Z, Cai J, Huang L, Zhu H \& Luo Y 2019 Potential role of microRNA-424 in regulating ERRgamma to suppress trophoblast proliferation and invasion in fetal growth restriction. Placenta 83 57-62. (https://doi.org/10.1016/j.placenta.2019.07.001)

Received 18 May 2020

First decision 29 June 2020

Revised Manuscript received 11 December 2020

Accepted 18 December 2020 